\title{
An Immunohistochemical Study of the Nerve Growth Factor Receptor in Developing Rats
}

\author{
Qiao Yan and Eugene M. Johnson, Jr. \\ Department of Pharmacology, Washington University School of Medicine, St. Louis, Missouri 63110
}

Nerve growth factor (NGF) receptor expression was studied in rats between embryonic day 11 (E11) to postnatal day 10 (PND10) by using a monoclonal antibody, 192-IgG, that specifically recognizes rat NGF receptor. Sympathetic ganglia were lightly stained by 192-IgG for NGF receptor immunoreactivity (NGFRI) (E11-PND10). Neural crest-derived sensory ganglia were moderately to densely stained (E11PND10). Areas in CNS innervated by the central processes of these ganglia were also stained. Parasympathetic ciliary ganglion showed some detectable staining (E16-PND6). Placode-derived sensory ganglia were stained more densely than that of neural crest-derived sensory ganglia. The most densely stained tissue for NGFRI was found in all peripheral nerves. Basal forebrain cholinergic neurons were NGFRI positive from E15 throughout the period examined. Motoneurons in both spinal cord and brain stem were positive for NGFRI between E15 and PND10. NGFRI staining was seen in a variety of sensory pathways and related structures, such as olfactory tract and glomerular layer of olfactory bulb; retina, optic nerve and tract, lateral geniculate nucleus, medial terminal nucleus of the accessory optic tract, and olivary pretectal nucleus; ventral cochlear nucleus and to a lesser degree in dorsal cochlear nucleus, superior olive, and nucleus of lateral lemniscus; solitary tract; cuneate nucleus, gracile nucleus, and ventroposterior thalamic nucleus. The specific staining was also found in some other CNS structures, including brain-stem reticular formation; amygdala; medial nucleus of inferior olive but not the rest of inferior olive, external granule cell layer and Purkinje's cells of cerebellum, and deep cerebellar nuclei. Some non-neuronal tissues such as meninges and dental tissue showed very distinctive staining. Limb buds and somites were NGFRI positive starting at $E 11$, and the staining on muscle tissue became very dense at E15-E18 and largely disappeared around PND10. Embryonic thymus was positive for NGFRI. The adventitia surrounding blood vessels was very densely stained.

The changes in NGFRI staining seen in this study suggest that NGF may have broader effects during development than previously thought.

\footnotetext{
Received Nov. 5, 1987; accepted Jan. 12, 1988

We wish to thank Dr. Thomas A. Woolsey for the use of his laboratory equipment and helpful discussion of results. We also wish to thank Drs. Lawrence F. Kromer, Joseph L. Price, David Menton, and Barbara Bohne for valuable discussion of results and Mr. David Martin, Ms. Pat Osborne, and Dr. Ian Ferguson for reading the manuscript, and Jenny Colombo for general laboratory assistance. This work was supported by NIH Grants NS18071 and NS24679.

Correspondence should be addressed to Eugene M. Johnson, Jr., Ph.D., Department of Pharmacology, Box 8103, Washington University School of Medicine, 660 South Euclid Avenue, St. Louis, MO 63110.

Copyright (C 1988 Society for Neuroscience $0270-6474 / 88 / 093481-18 \$ 02.00 / 0$
}

Nerve growth factor (NGF) is essential for the development and maintenance of the function of peripheral sympathetic ncurons and neural crest-derived sensory neurons (Levi-Montalcini and Angeletti, 1968; Johnson et al., 1980). Recent experiments show that NGF also has effects on central cholinergic neurons in basal forebrain (Gnahn et al., 1983) and striatum (Mobley et al., 1985).

Although the precise biochemical mechanism(s) by which the effects of NGF are mediated is unknown, NGF binding with the surface receptor on NGF-responsive cells is an essential step for NGF to produce its biological effects. The expression of NGF receptor is regarded as a prerequisite for a tissue to be NGF responsive. It has been shown that the expression of NGF binding sites is developmentally regulated in a broad range of tissues in chicken embryo by autoradiographic studies (Raivich et al., 1985, 1987) and in rats by a quantitative immunoprecipitation assay (Yan and Johnson, 1987). It is clear from these studies that NGF receptor is expressed very early in development. In most tissues the NGF receptor level is decreased during development (Yan and Johnson, 1987). The studies in chick embryo (Raivich et al., 1985, 1987) show a wide distribution of specific NGF binding sites, but so far there has been no systematic morphological study of NGF receptor in mammalian development. The temporal change of NGF dependence of embryonic avian dorsal root ganglion (DRG) is somewhat disparate from that of mammalian DRG (Herrup and Shooter, 1975; Stockel et al., 1975; Barde et al., 1980; Johnson et al., 1980), which suggested that the expression of NGF receptor in these different species might be different. Here we used a specific antirat NGF receptor monoclonal antibody, 192-IgG (Chandler et al., 1984; Taniuchi and Johnson, 1985), for immunohistochemical study to localize NGF receptor in developing rats. The NGF receptor immunoreactivities (NGFRI) were found in all the classical NGF targets such as peripheral sympathetic and sensory neurons, as well as basal forebrain cholinergic neurons. The data also show many other, unexpected NGF receptor-immunopositive sites.

\section{Materials and Methods}

Materials. Mouse anti-rat NGF receptor monoclonal antibody (192IgG) (Chandler et al., 1984) was affinity-purified as previously described (Yan and Johnson, 1987). Anti-mouse antibody ABC-peroxidase kits were purchased from Vector Lab (Burlingame, CA). Na ${ }^{125} 1(100 \mathrm{mCi}$ / ml) was purchased from Amersham (Chicago). Other chemicals were obtained from Sigma (St. Louis).

Animals and tissue sectioning. Sprague-Dawley rats (Chappel Breeders, St. Louis) were used. Vaginal plug positive is recorded as embryonic day zero (E0). Parturition is between E21 to E22, taken as postnatal day zero (PND0). Timed-pregnant rats were killed by decapitation under light ether anesthesia, and embryos were quickly removed from the uterus. Embryos younger than E18 were immersion-fixed. E18 and older animals were perfused through the left ventricle of the heart with PBS, 

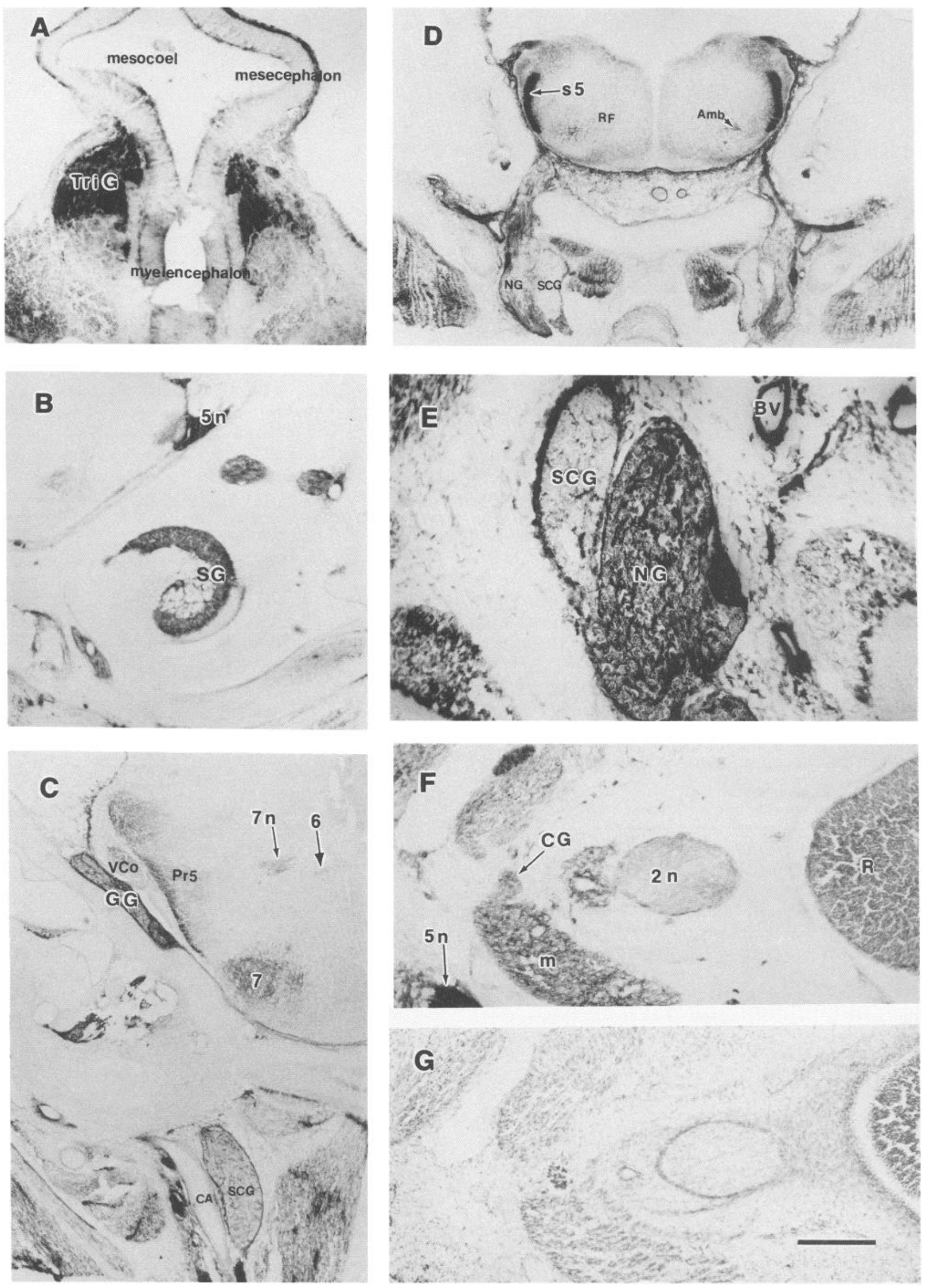
pH 7.4, followed by fixative. Both 1 and 4\% paraformaldehyde in 0.1 M sodium phosphate buffer, $\mathrm{pH} 7.4$, were used in initial experiments. The immunoreactivity was decreased only slightly at the higher concentration. Most data in this report came from $4 \%$ paraformaldehydefixed tissues. Tissues were postfixed overnight (prolonged fixation would greatly decrease the immunoreactivity), equilibrated with $30 \%$ sucrose, and frozen in an isobutane/dry ice bath. Fourteen- to twenty-micron sections were cut with a cryostat $\left(-20^{\circ} \mathrm{C}\right)$, mounted on chrome-alumcoated slides, and air-dried.

Immunohistochemistry with 192-IgG. The indirect immunohistochemistry was carried out by using the avidin-biotin-peroxidase complex $(A B C)$ method (Vectastain, Vector Laboratories) as described below. After preincubation with $0.003 \%$ hydrogen peroxide in absolute methanol for $1 \mathrm{hr}$ at room temperature (RT) to inhibit endogenous peroxidase, sections were incubated overnight at $4^{\circ} \mathrm{C}$ with $2 \mu \mathrm{g} / \mathrm{ml}$ of $192-\mathrm{IgG}$ or any of several control antibodies in PBS $/ 10 \%$ horse serum, $\mathrm{pH}$ 7.4. The sections were washed 3 times in PBS, 10 min each at RT (same wash procedure was performed between each of the following steps), and incubated overnight at $4{ }^{\circ} \mathrm{C}$ with biotinylated secondary antimouse antibodies, dilution 1:300 in PBS/10\% horse serum, $\mathrm{pH}$ 7.4. The sections were incubated for $3 \mathrm{hr}$ at RT with gentle agitation with a solution containing a preformed avidin/biotin-peroxidase complex, at a dilution of $1: 250$ in PBS, pH 7.4. The sections were then incubated with 3,3'-diaminobenzidine tetrahydrochloride (DAB) reaction solution $(0.05 \% \mathrm{DAB} / 0.017 \%$ cobalt chloride $/ 0.0136 \%$ nickel ammonium sulfate $/ 0.1 \mathrm{M}$ phosphate buffer, $\mathrm{pH} 7.6$ ) for $10 \mathrm{~min}$, and then $0.0066 \%$ hydrogen peroxide was added to the DAB solution for another 5-10 $\min$. The reaction took place at $\mathrm{RT}$ with agitation. The sections were then dehydrated and coverslips applied.

Quantitative immunoprecipitation assay for NGF receptor. Mouse NGF (2.5S) was purified from male mouse submaxillary glands by the method of Bocchini and Angeletti (1969) and iodinated (Marchalonis, 1969) to obtain a specific activity of $2200 \mathrm{cpm} / \mathrm{fmol}$. NGF receptors in SCG and nodose ganglia were quantitated in duplicates of tissue homogenates by using a 2-sitc immunoprecipitation assay (Taniuchi et al., 1986b) modified as previously described (Yan and Johnson, 1987).

\section{Results}

\section{Specificity of 192-IgG immunohistochemistry}

Four different control antibodies were used to test the specificity of the immunochemical method with 192-IgG: (1) mouse myeloma IgG protein (from Litton Bionetics); (2) mouse monoclonal antibody, 151-IgG, generated against PC12 cell-EGF receptur; (3) ascites-containing mouse monoclonal antibody (IgG) against chick glutamic acid decarboxylase (kindly provided by Dr. D. Gottlieb); and (4) another mouse monoclonal antibody (IgG2b) against an unknown antigen. All of these control monoclonal antibodies failed to show positive staining. One example is shown in Figure $2 F$ which uses mouse myeloma IgG protein as the primary antibody.

Because 192-IgG has been shown to be species-specific (Taniuchi and Johnson, 1985), whole-embryo sections of E15 hamster were stained with 192-IgG. No staining was observed in hamster embryos (data not shown).

\section{Peripheral ganglia and related structures}

Sympathetic ganglia were NGFRI positive in all animals where ganglia were distinct (Table 1). The density of staining was light and did not appear to vary with age (Fig. $1 C-E$ ). For neural crest-derived sensory ganglia, NGFRI was found in the trigeminal ganglion (Fig. 1 $A$ ), rostral DRG, and potential caudal DRG region (lateral to spinal cord) as early as E11 (Fig. 2, $A$ and $B$ ). At this stage, some caudal DRG were not discrete structures and might still have been in the process of DRG formation and neural crest cell migration (Fig. $2 B$ ); this suggests that the migrating neural crest cells might be NGFRI positive. At E13 all the DRG were distinct structures that showed relatively low NGFRI staining levels (Fig. 2C). The staining density in DRG increased and became quite dense between F1 8 to PND0 (Figs. $2 E, 5 D$ ). The staining of jugular ganglion (Fig. $5 C$ ), also a neural crest-derived sensory ganglion, was basically the same as that of DRG. Trigeminal ganglia showed a similar, but slightly more intense, temporal pattern of staining. The staining density in all these neural crest-derived sensory ganglia was reduced by PND6 and further declined in PND10 DRG (Table 1), consistent with our previous quantitative biochemical data (Yan and Johnson, 1987).

Placode-derived sensory ganglia showed a surprisingly intense NGFRI staining with 192-IgG (Table 1). Otic vesicle was NGFRI positive at E11-E13. The geniculate ganglion of seventh nerve, the spiral cochlear ganglion and vestibular ganglion of eighth nerve, and nodose ganglion (Fig. $1 D$ ) of tenth nerve were moderately stained at E15-E 16 . The staining became very intense between E18 to PND6 (Figs. 1, B, C, E; 5, B, $C$; and Table 1). The density of staining in placode-derived sensory ganglia was somewhat greater than that in neural crest-derived sensory ganglia and much higher than that in sympathetic ganglia. Figure $1, D$, and $E$, shows both SCG and nodose ganglia side by side in the same sections. The nodose ganglion was much more densely stained. In order to verify that the NGFRI staining seen in nodose ganglion, which is not an NGF-dependent structure (Johnson et al., 1980), reflects true NGF receptor, the NGF receptor levels were determined by the 2-site immunoprecipitation assay (Taniuchi et al., 1986b). The NGF receptor was measured in homogenates of PND0 SCG and nodose ganglia. The NGF receptor density was about $50 \%$ higher in nodose ganglia ( $83.3 \mathrm{fmol} / \mathrm{mg}$ protein) than in SCG $(54.2 \mathrm{fmol} / \mathrm{mg}$ protein). The possible biological significance of this finding will be discussed. Parasympathetic ciliary ganglia, which are neural crestderived but NGF independent (Pearson et al., 1983; Dimberg and Ebendal, 1987), were stained lightly by $192-\operatorname{IgG}$ between E16 and PND6 (Fig. 1, $F, G$ ), although it was not clear whether the staining was on neuronal and/or non-neuronal cells.

Some enteric cellular components in E13 gut were positive for NGFRI (Fig. 3A). This was not seen in E15 (Fig. 3B) or E11 embryos. These NGFRI-positive cells, although transient, had very dense staining on their cell bodies and processes. It has heen reported that tyrosine hydroxylase immunoreactivity and catecholamine histofluorescence are first detectable in scattered, presumptive neuroblasts in the rat gut at E11.5. Thereafter, they decrease progressively; by E14.5, only rare cells are encountered (Cochard et al., 1978; Jonakait et al., 1979). The temporal and

\section{$\leftarrow$}

Figure 1. 192-IgG immunohistochemical staining of peripheral ganglia. $A$. Frontal section through the mesencephalon and myelencephalon at E11. $B$, Cross section of E18 spiral cochlear ganglion (SG). C, Cross section of E18 head. $D$, Cross section through nodose ganglion $(N G)$ and superior cervical ganglion (SCG) at E16. E, Cross section through NG and SCG at E18. F, Cross section through E18 head showing ciliary ganglion ( $C G$ ). $G$, H\&E staining of the adjacent section of $F$. $2 n$, optic nerve; $5 n$, trigeminal nerve; 6 , abducens nucleus; 7 , facial nucleus; $7 n$, facial nerve; $A m b$, ambiguus nucleus; $B V$, blood vessel; $C A$, internal carotid artery; $G G$, geniculate ganglion; $m$, muscle; $\operatorname{Pr} 5$, principal sensory trigeminal nucleus; $R$, retina; $R F$, reticular formation; $s 5$, sensory root of the trigeminal nerve; Tri.G, trigeminal ganglion; $V C o$, ventral cochlear nucleus. Scale bar (in $G): 200 \mu \mathrm{m}, A$ and $E-G ; 500 \mu \mathrm{m}, B-D$. 

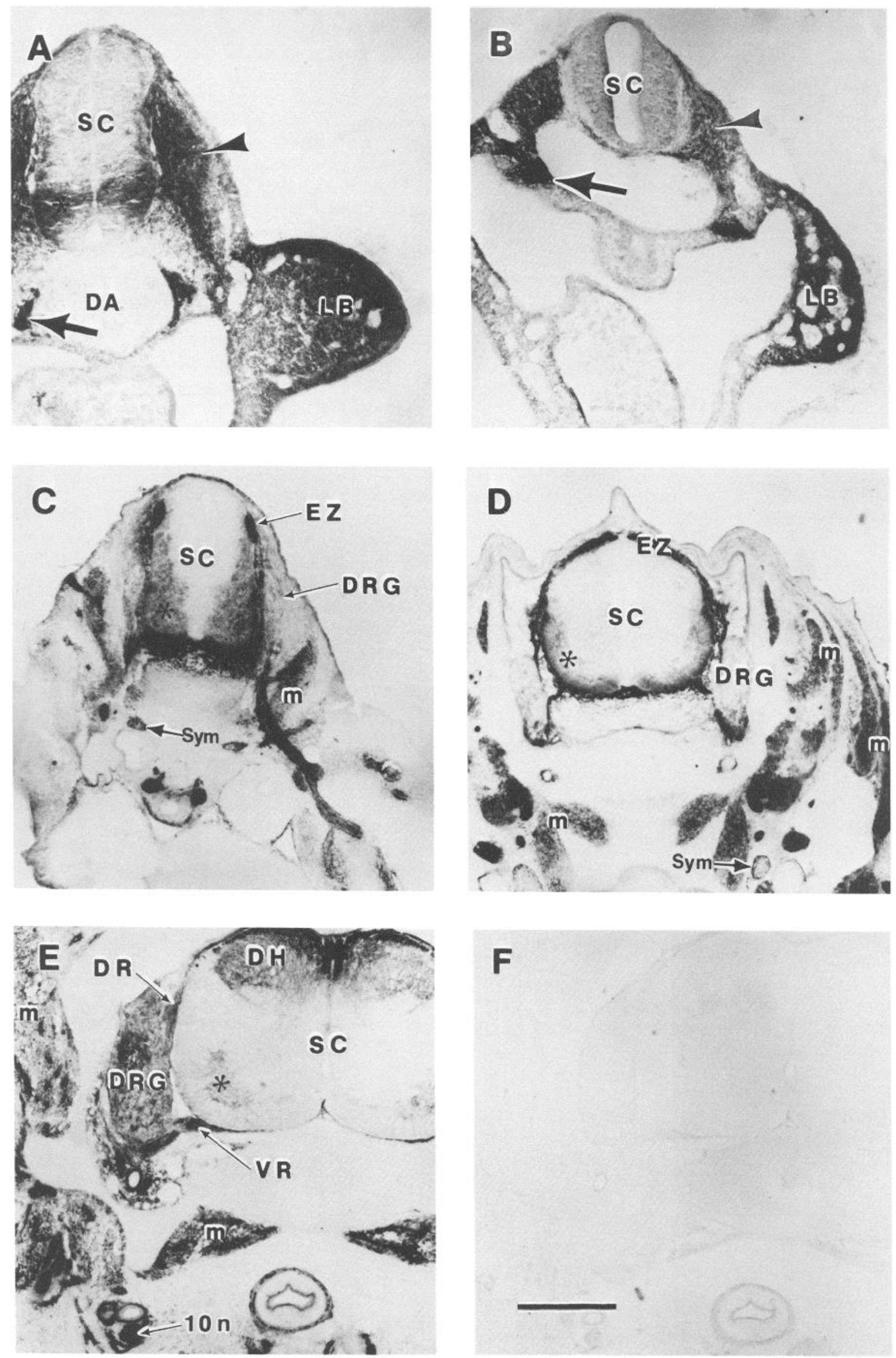

F 


\begin{tabular}{|c|c|c|c|c|c|c|c|c|c|c|c|}
\hline Tissue & E11 & E12 & E13 & E14 & E15 & E16 & E18 & $\mathrm{E} 20$ & PO & P6 & P10 \\
\hline Nerves & nd & + & +++ & +++ & +++ & $+t+$ & ++ & +++ & +++ & ++ & + \\
\hline \multicolumn{12}{|c|}{ Neural crest-derived ganglia } \\
\hline Trigeminal & + & + & + & \pm & \pm & + & ++ & ++ & ++ & + & nd \\
\hline Jugular & nd & nd & nd & nd & \pm & + & ++ & ++ & + & + & nd \\
\hline DRG & ++ & ++ & + & \pm & \pm & + & ++ & ++ & ++ & + & $\perp$ \\
\hline Sympathetic & + & + & + & + & + & + & + & + & + & + & + \\
\hline \multicolumn{12}{|c|}{ Placode-derived ganglia ${ }^{b}$} \\
\hline Geniculate & nd & nd & nd & nd & + & + & ++ & ++ & ++ & + & nd \\
\hline Cochlear & nd & nd & nd & nd & + & + & +++ & ++ & ++ & ++ & nd \\
\hline Vestibular & nd & nd & nd & nd & + & + & +++ & ++ & ++ & ++ & nd \\
\hline Nodose & nd & nd & nd & nd & + & + & +++ & $+t$ & nd & nd & nd \\
\hline Ciliary ganglion & nd & nd & nd & nd & nd & + & + & + & + & \pm & nd \\
\hline
\end{tabular}

${ }^{a}$ Relative NGFRI staining intensities are graded: +++ , very strong; ++ , strong; + , moderate to weak; \pm , faint; - , absent; nd, not determined.

${ }^{b}$ Otic vesicle was NGFRI positive at EI $1-\mathrm{E} 12$.

spatial correlations between the expression of NGFRI and the catecholaminergic phenotypic characteristics in neuroblasts of rat embryonic gut suggest that these might be the same neurons. Some unidentified cells in E1 1 heart were also very densely stained for NGFRI (Fig. 3C).

\section{Peripheral nerves}

All peripheral nerves, when clearly discernible, were intensely stained for NGFRI (E13 and later; Fig. 2C). For example, dorsal root (sensory), ventral root (motor) of spinal nerve, vagus nerve (placode-derived sensory and parasympathetic), and other unidentified nerves all showed very intense staining (Fig. 2, $C, E$ ). Although the resolution at the light microscopic level was not sufficient to determine whether NGFRI was on Schwann cells or on axons, the fact that all peripheral nerves were NGFRI positive suggests that the common component of peripheral nerve, the Schwann cell, contributes most of this NGFRI staining. The possibility that all the peripheral axons were NGFRI positive at certain developmental stages cannot be excluded.

\section{Basal forebrain cholinergic neurons}

Large cell bodies in basal forebrain regions, including medial septum, nucleus basalis, and the diagonal band of Broca, were NGFRI positive starting at about E15 (Table 4). They remained positive postnatally. Figure $4, A, B$, shows NGFRI-positive magnocellular neurons in the diagonal band of Broca of an E20 basal forebrain. Although a double-labeling study has not been done to determine the neurotransmitler phenotype of these neurons, the anatomical localization of these NGFRI-positive cells suggests that they were basal forebrain cholinergic neurons.

\section{Spinal and brain-stem motoneurons}

In spinal cord, NGFRI first appeared in the rostral portion of ventral spinal cord as early as E1 1 (Fig. $2 A$ ) but not in the caudal portion of ventral spinal cord (Fig. 2B). At E13, NGFRI staining in the ventral spinal cord became denser (Fig. $2 C$ ). The caudal portion of E13 spinal cord showed an NGFRI staining pattern similar to rostral E11 spinal cord, indicating there was a rostral to caudal gradient of expression of NGFRI, which is consistent with the rostral to caudal development of the whole spinal cord in general. At E15 the staining was much reduced in ventral spinal cord, and the staining became localized to the lateral motor column (Fig. 2D). The staining in lateral motor column was increased at E18 (Fig. $2 E$ ) and reached its peak around PND0 (Fig. 5D). It decreased afterward and disappeared by PND10 (Table 2). The staining was on the large cell bodies and dendrites of presumptive motoneurons (Fig. 5). Monosynaptic projections from the DRG to motoneurons might also contribute part of this staining because some fibers that entered the dorsal root and extended to the ventral horn were NGFRI positive (Figs. $2 E, 5 D, 6 F$ ). Brain-stem motor nuclei were also NGFRI positive at about the same period as the lateral motor column in spinal cord. The trigeminal motor nucleus (Fig. $5 B$ ), abducens nucleus (Fig. 1C), facial nucleus (Fig. 1C), hypoglossal nucleus (Fig. 5A), and ambiguus nucleus (Figs. $1 D ; 5, A, C$ ) were NGFRI positive starting around E15/E16. As with spinal cord motoneurons, staining disappeared around PND10 (Table 2). Dorsal motor nucleus of vagus was slightly positive at E18 (Fig. 6A).

\section{Sensory pathways and nuclei in CNS}

The area in the brain stem occupied by trigeminal ganglia central processes was NGFRI positive as early as E11, and this persisted to the postnatal period (Table 3 ). The sensory root and spinal tract of trigeminal nerve were very densely stained, and the density was similar to that of peripheral nerves (Figs. $1 C ; 5 C$; $6 A, E$ ). The trigeminal sensory nucleus was stained much less densely than the nerve tract. The mesencephalic tract of the

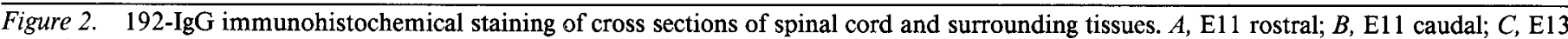

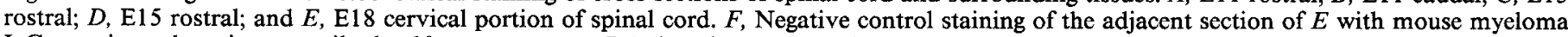

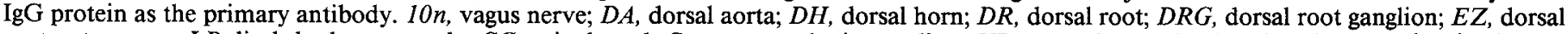

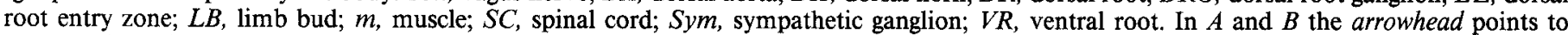

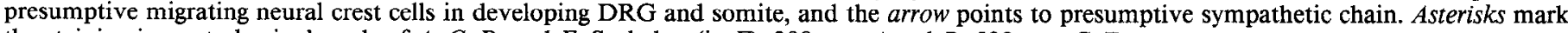
the staining in ventral spinal cords of $A, C, D$, and $E$. Scale bar (in $F$ ): $200 \mu \mathrm{m}, A$ and $B ; 500 \mu \mathrm{m}, C-F$. 
3486 Yan and Johnson, Jr. • Immunohistochemical Study of NGF Receptor
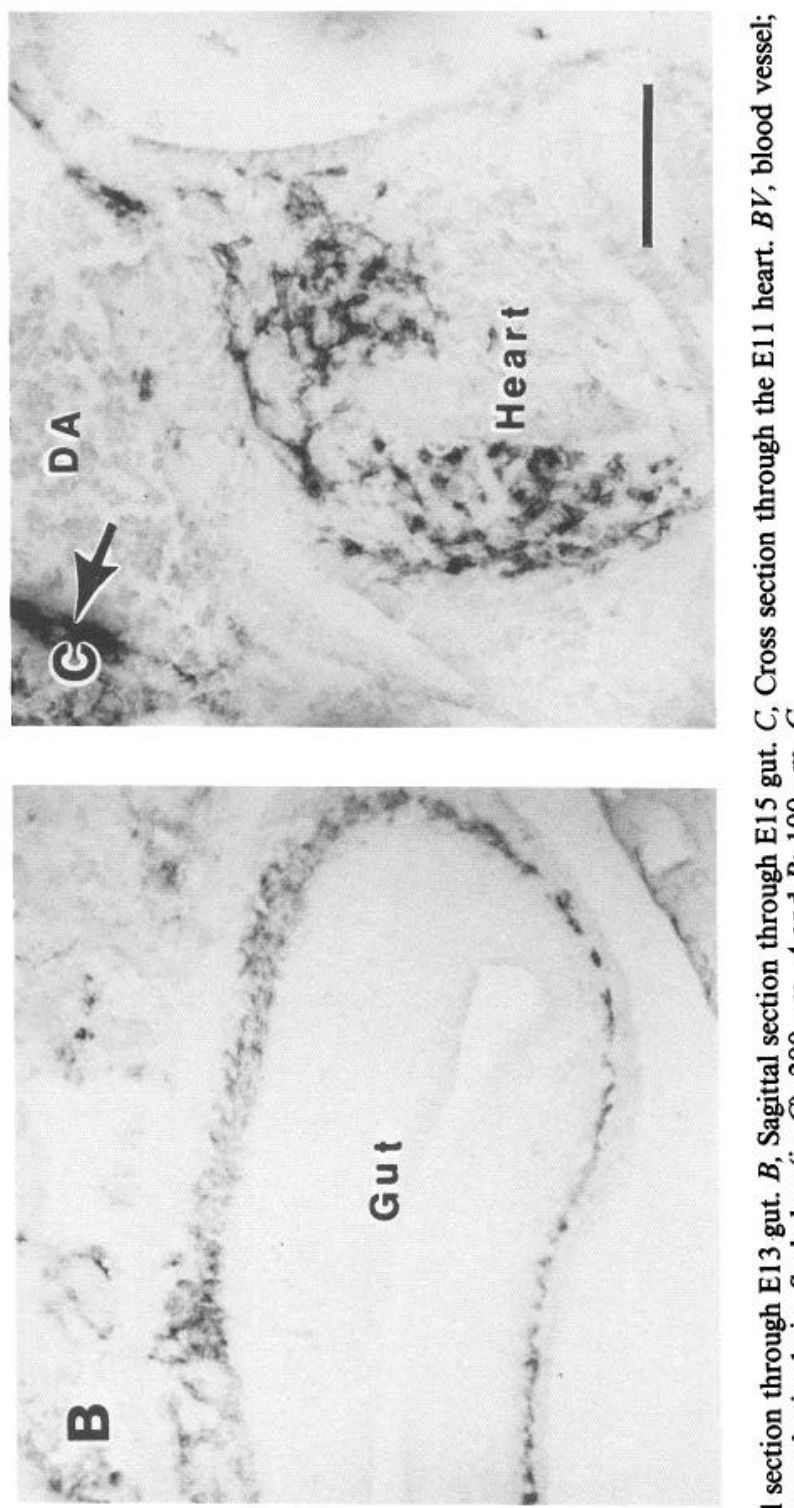

范

또으

땔

อี้

ชี

串

莺

$\infty .5$

范

ตี

홀.

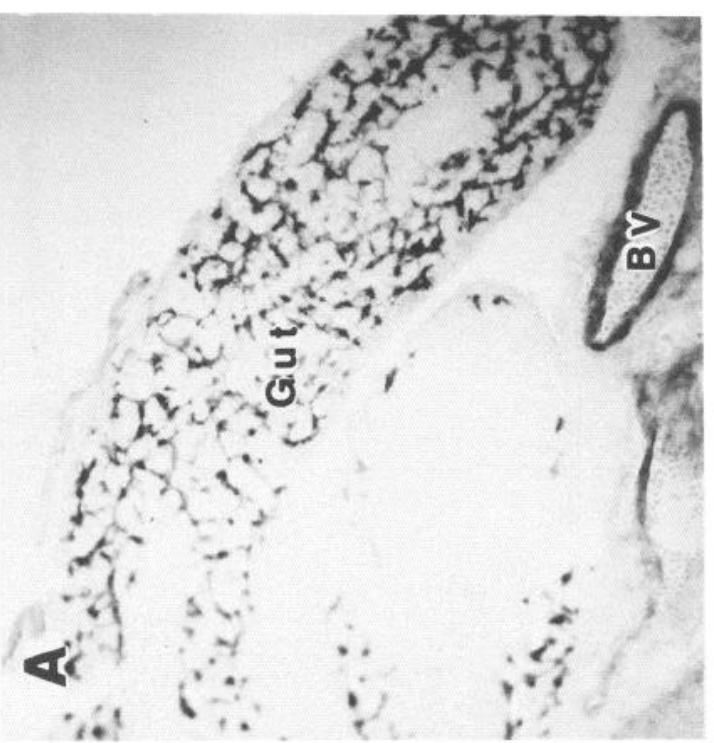

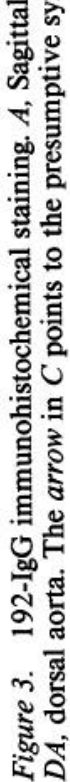



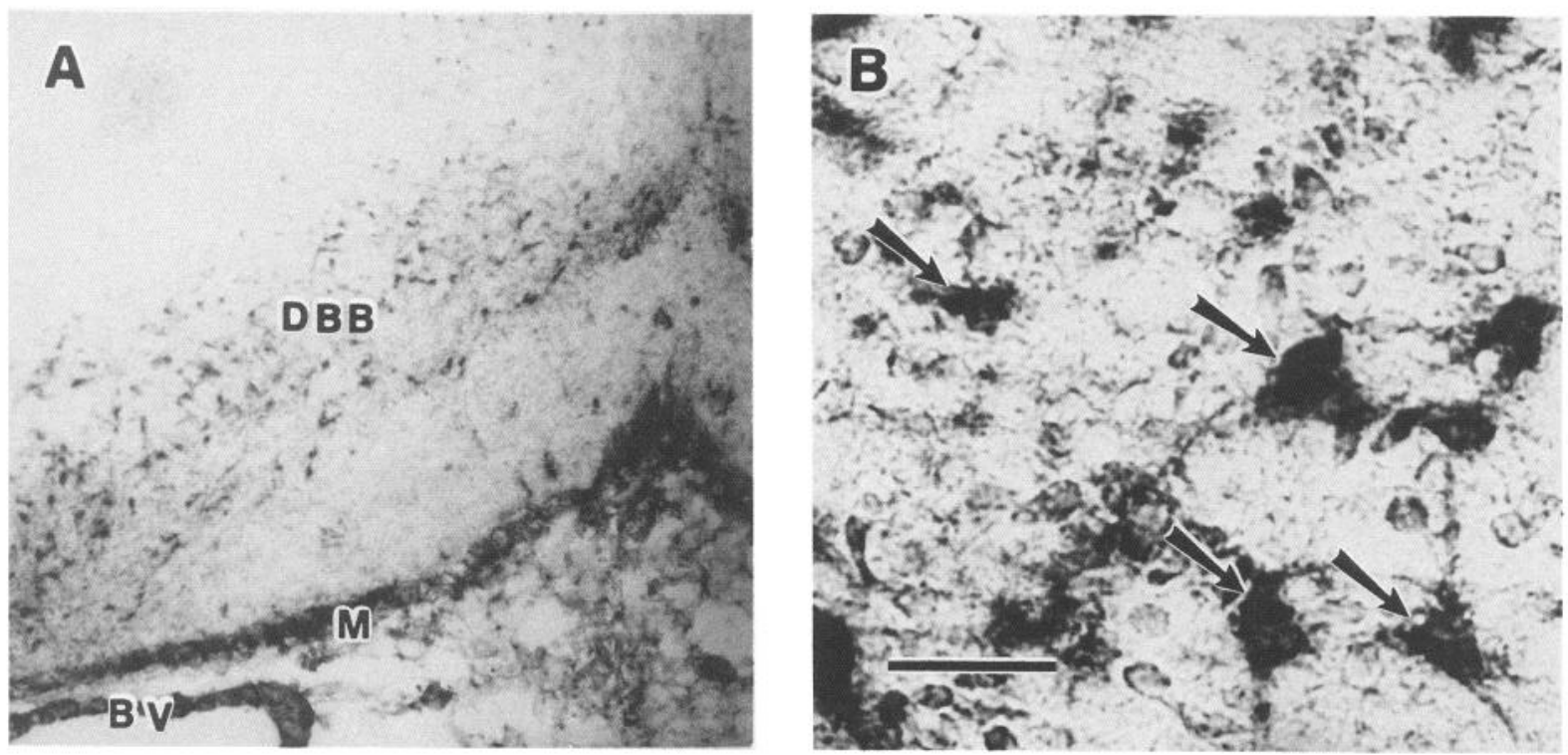

Figure 4. $A$, 192-IgG-positive neurons in diagonal band of Broca $(D B B)$ of E20 basal forebrain. $B$, High-power view. Arrows point to magnocellular neurons. Meninges $(M)$ and blood vessels $(B V)$ are also 192-IgG positive. Scale bar (in $B$ ): $200 \mu \mathrm{m}, A ; 20 \mu \mathrm{m}, B$.

trigeminal nerve and its nucleus were NGFRI negative. NGFRI expression began at the dorsal entry zone of spinal cord at E13 (Fig. $2 C$ ). The dorsal horn of spinal cord became NGFRI positive at E15 (Fig. 2D), and the staining increased to its peak between $\mathrm{E} 18$ (Fig. $2 E$ ) and PND0 (Fig. 5D), then declined slowly. At PND10 there was some staining in the dorsal horn and trigeminal nerve terminal region (Fig. $8 A$ ), which persists into adulthood (Yip and Johnson, 1987). The dorsal fasciculus of spinal cord (Figs. $2 E, 5 D$ ) and cuneate and gracile nuclei (Fig. $6, A, B)$ were also NGFRI positive. Like the situation in trigeminal system, sensory nerve tracts were stained much more densely than their associated nuclei. The medial lemniscus was NGFRI negative at all stages examined. Ventroposterior thalamic nucleus was diffusely stained for NGFRI starting around E16, and this staining persisted to postnatal stages (Fig. 6C).

The nerve tract and glomeruli in glomerular layer of olfactory bulb was NGFRI positive starting at approximately E14, when the structure could be identified, and the staining persisted to PND10 (Fig. 7, $A, B$ ). The termini of olfactory nerve in nasal cavity were well stained at prenatal stage (Fig. $7 A$ ).

The retina and optic nerve were also NGFRI positive. The internal layer, the ganglion layer, of the retina showed NGFRI staining at E16. The retina, especially the ganglion layer, was densely stained at E20 (Fig. 7C). The staining decreased at PND6 and disappeared at PND10. At E15 the optic nerve and tract showed slight NGFRI staining. The density of staining increased at E16-E20 and decreased postnatally. At PND10 there was still some diffuse staining in these structures (Fig. $6 \mathrm{C}$ ). The lateral geniculate nucleus was positive for NGFRI staining between E16 to PND10 (Fig. 6C). At PND10, the staining in the ventral nucleus of lateral geniculate was denser than the dorsal nucleus. For the dorsal nucleus of lateral geniculate, only the anterior part stained; the posterior part remained negative. Some other visual-related brain structures in PND0-PND10 animals were also positively stained. These structures included the lateral part of superior colliculus but not the medial part (Fig. 9A); the olivary pretectal nucleus (Fig. $7 D$ ); and the medial terminal nucleus of the accessory optic tract (Fig. $7 E$ ). The staining in these areas was mainly related to fiber tracts.

The cochlear nucleus was NGFRI positive between E16 to PND10. In the postnatal animals, the staining in ventral cochlear nucleus was distinct, while the dorsal cochlear nucleus was stained more lightly (Fig. 6D). Between E16 and PND0, the superior olive was stained (Fig. $6 E$ ); this staining declined at PND6 and disappeared by PND10. The lateral lemniscus together with its nucleus were lightly stained (Fig. $6 E$ ). Staining was not detected in medial geniculate nucleus and inferior colliculus.

Table 2. NGFRI in CNS motor system ${ }^{a}$

\begin{tabular}{llllllllllll} 
Tissue & E11 & E12 & E13 & E14 & E15 & E16 & E18 & E20 & P0 & P6 & P10 \\
\hline Trigeminal motor nucleus & nd & nd & nd & nd & \pm & ++ & + & + & + & \pm & - \\
Abducens nucleus & nd & nd & nd & nd & + & + & + & \pm & - & - & - \\
Facial nucleus & nd & nd & nd & nd & \pm & + & + & + & + & \pm & - \\
Hypoglossal nucleus & nd & nd & nd & + & + & ++ & + & + & + & + & - \\
Ambiguus nucleus & nd & nd & nd & nd & + & + & + & + & + & + & - \\
Spinal motoneuron $^{b}$ & + & + & + & \pm & \pm & + & + & + & ++ & + & -
\end{tabular}

$\bar{a}$ Relative NGFRI staining intensities are graded: +++ , very strong; ++ , strong; + , moderate to weak; \pm , faint; - , absent; nd, not determined.

${ }^{b}$ Staining was in ventral spinal cord at E11-E13. 

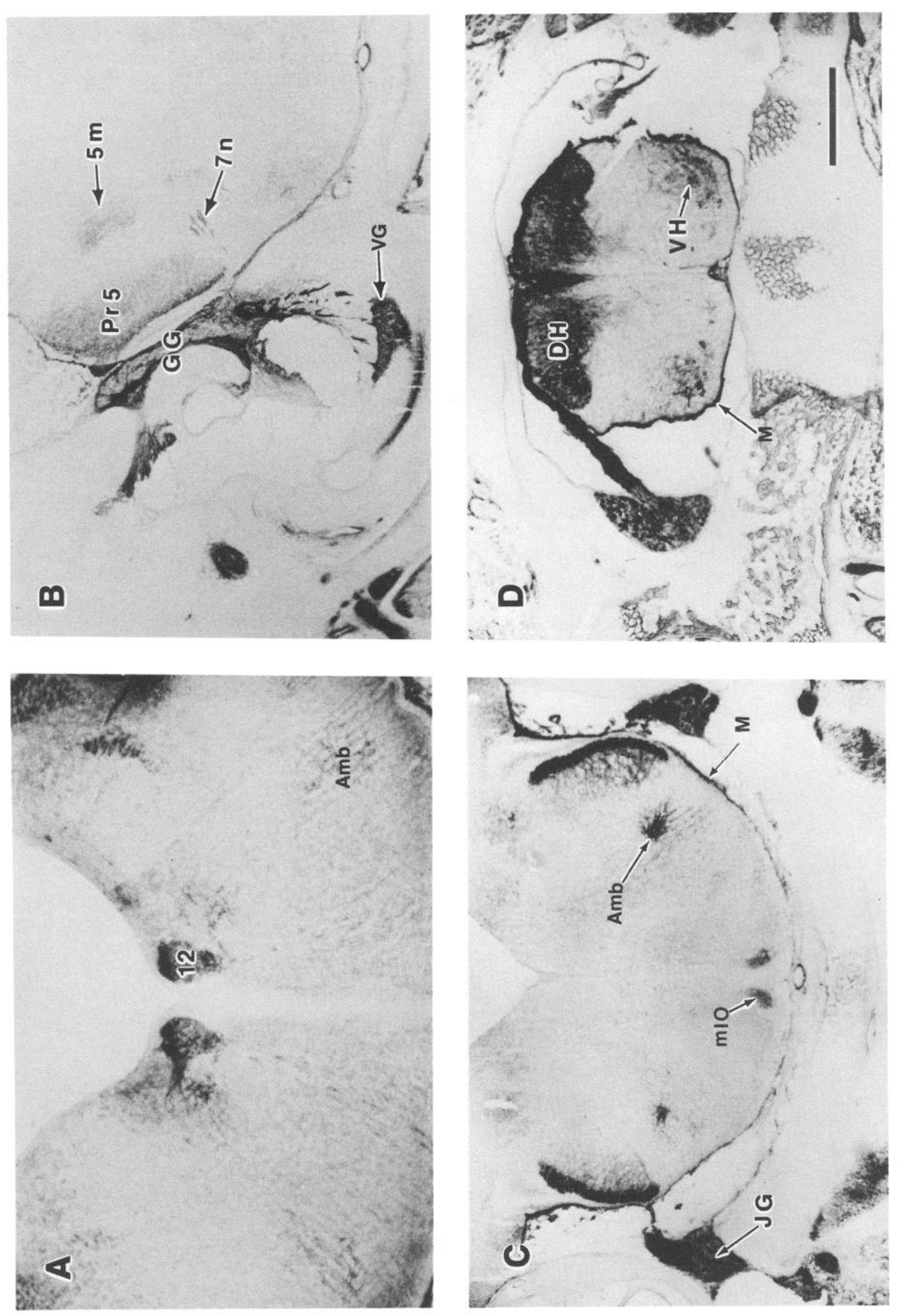

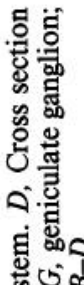

采

象

西要華

웡

올

幽

药

U렬

ن产总

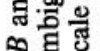

वृ

हี่ है ह

고 슬

s.

길

语

도음

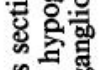

政

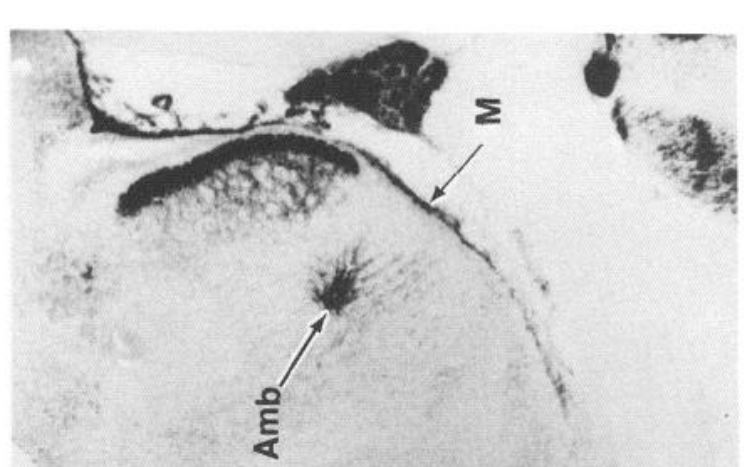

0 .

तं

ठ․ㅀ

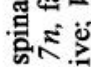

하응

즐.

के

명융당

영멸

녕 플

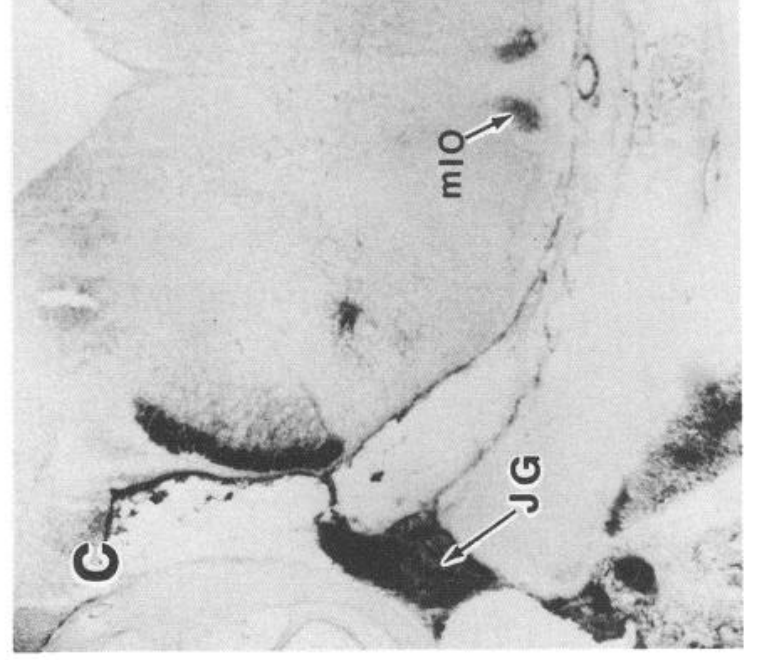

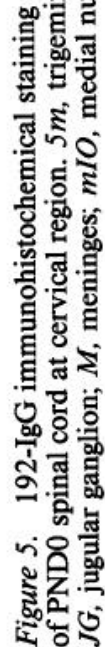



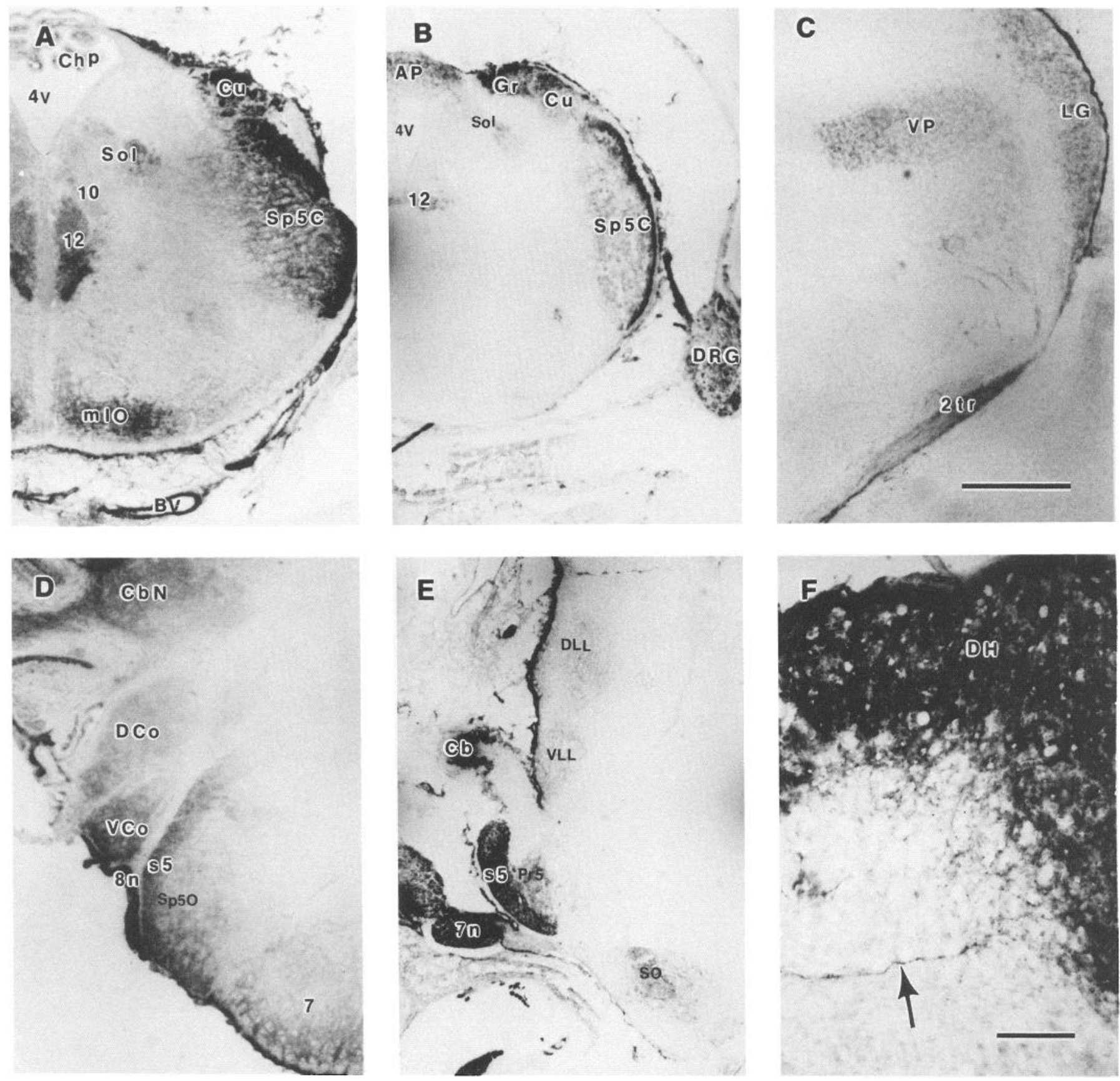

Figure 6. 192-IgG immunohistochemical staining of some CNS sensory structures. A, Cross section of E18 brain stem. B, Cross section of E20 brain stem. $C$, Cross section of PND0 thalamus. $D$, Cross section of PND6 brain stem and cerebellum. $E$, Cross section of PND6 brain stem. $F$, Cross section of PO spinal cord. $2 t r$, optic tract; $4 V$, fourth ventricle; 7 , facial nucleus; $7 n$, facial nerve; $8 n$, cochlear nerve; 10 , dorsal motor nucleus of vagus; 12 , hypoglossal nucleus; $A p$, area postrema; $B V$, blood vessel; $C b$, cerebellum; $C b N$, deep cerebellar nuclei; $C h P$, choroid plexus; $C u$, cuneate nucleus; $D C o$, dorsal cochlear nucleus; $D H$, dorsal horn; $D L L$, dorsal nucleus of lateral lemniscus; $D R G$, dorsal root ganglion; $G r$, gracile nucleus; $L G$, lateral geniculate nucleus; $m I O$, medial nucleus of inferior olive; $\operatorname{Pr} 5$, principal nucleus of trigeminal nerve; $s 5$, spinal tract of trigeminal nerve; $S O$, superior olive; sol, solitary tract and its nucleus; $S p 5 C$, spinal tract of the trigeminal nerve and its nucleus (pars caudalis); $S p 50$, spinal tract of trigeminal nerve and its nucleus (pars oralis); $V C o$, ventral cochlear nucleus. Arrow in $F$ points to a fiber cross from dorsal horn to contralateral side (left). Scale bar in $C: 500 \mu \mathrm{m}, A, C$, and $D ;$ scale bar in $F: 500 \mu \mathrm{m}, B$ and $E ; 100 \mu \mathrm{m}, F$.

The solitary tract was distinctly stained, and there was light staining on the nucleus of the solitary tract between E16 and PND6, which disappeared at PND10 (Fig. 6, $A, B$ ).

\section{Cerebellum and related structures}

Some fiber tracts in E16 cerebellar anlage were stained by 192IgG (Fig. 8C); these fibers extended to mesencephalon. At E18 the staining in cerebellar anlage spread to the whole structure. The density of staining increased afterwards. The NGFRI staining in cerebellar Purkinje cells, including dendrites, was clearly seen at PND6, when the different layers of cerebellum were well established (Table 4 ). The staining became very prominent at PND10 (Fig. 8, $A, B$ ) and could be seen clearly on the cell surface. Very intense NGFRI staining was also present on ex- 

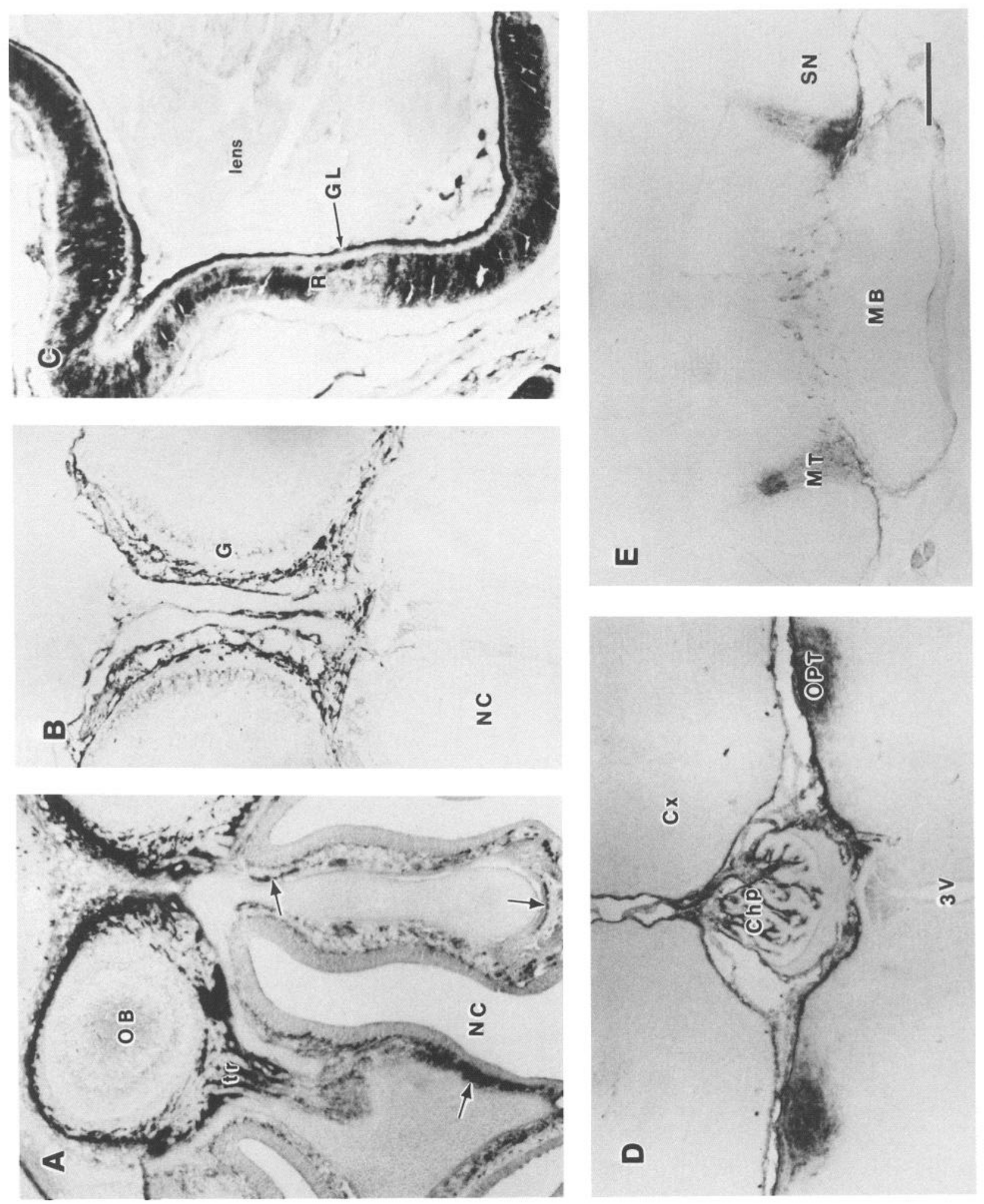

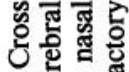

U⿺辶寸

ฮึ่

鸰藻

递宽

뭉항

인

ㄷㅇㅇ용.

.

ส용

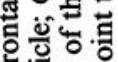

政要

$\rightarrow$ ए

๖o

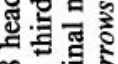

$\infty$ ㅊ

实

承

ㅎㅇㅇㅝ

证

霖

管

至娄

응을

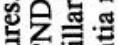

员

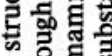

댕혀

현

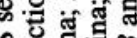

乙业象

o 5 次

궁요요

엥요

o

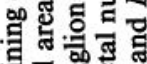

편

नु⿺워

붕영

등형응

क्ष

类幽

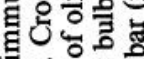

००:=

엉

人。응

.

동

溇 


\section{Table 3. NGFRI in CNS sensory system ${ }^{a}$}

Tissue E11 E12 E13 E14 E15 E16 E18 E20 P0 P6 P10

Glomeruli and olfactory tract of olfactory bulb

Retina ${ }^{b}$

Optic nerve and tract

Trigeminal sensory nuclcus

Cochlear nucleus

Solitary tract and nucleus

Cuneate and gracile nucleus

Spinal cord dorsal horn ${ }^{d}$

$\begin{array}{cccc}\text { nd } & \text { nd } & \text { nd } & + \\ - & - & - & - \\ - & - & - & - \\ - & - & - & - \\ \text { nd } & \text { nd } & \text { nd } & \text { nd } \\ \text { nd } & \text { nd } & \text { nd } & \text { nd } \\ \text { nd } & \text { nd } & \text { nd } & \text { nd } \\ - & - & - & -\end{array}$

$\begin{array}{ll}+ & + \\ - & + \\ \pm & ++ \\ \pm & + \\ \text { nd } & + \\ \text { nd } & + \\ \text { nd } & + \\ \pm & ++\end{array}$

$\begin{array}{ll}+ & + \\ ++ & ++ \\ ++ & ++ \\ + & + \\ + & + \\ + & + \\ + & + \\ ++ & ++\end{array}$

$\begin{array}{lll}+ & + & + \\ + & + & - \\ + & + & \pm \\ + & + & + \\ + & + & \pm \\ + & + & - \\ + & + & - \\ ++ & + & +\end{array}$

${ }^{a}$ Relative NGFRI staining intensities are graded: +++ , very strong; ++ , strong; + , moderate to weak; \pm , faint; - , absent; nd, not determined. In all cases, staining was more intense in the sensory tract than that at the area of terminals. Staining at nuclei could not be clearly ascribed to cell bodies or terminals.

${ }^{b}$ For $\mathrm{E} 16$ retina, the staining was only seen in the ganglial layer.

Between E12 and E14, the staining was seen only at entry zone or nerve tract of trigeminal nerve.

${ }^{d}$ For E12-E14 dorsal spinal cord, the staining was restricted to the entry zone.

ternal granular cell layer at about the same time as the staining was visible on Purkinje cells (Fig. $8, A, B$ ). The deep cerebellar nuclei were also staincd for NGFRI during this period (Fig. 8A). The staining in cerebellum was completely gone at about PND15 (data not shown). The medial nucleus of inferior olive, but not other nuclei of inferior olive complex, was positive for NGFRI between E16 to PND6 (Fig. 8, D, E). The red nucleus was negative for NGFRI staining at all stages examined.

\section{Other brain structures}

Elements within the reticular formation in brain stem were moderately stained at E13-E16 (Figs. $1 D, 5 A$ ), lightly stained at E18 (Figs. 5, $B, C ; 6 A$ ), and not stained afterwards (Fig. 6, $B, E$ ). The amygdala complex was slightly stained for NGFRI between E20 and PND6 (Fig. 9B). The deep layer of cerebral cortex was diffusely stained between E18 to PND6 (Fig. 9A). Cells in ependymal and subependymal layer around the anterior part of the lateral ventricle extending from the olfactory bulb to caudate putamen region were NGFRI positive from E1 8 to all postnatal stages examined (Fig. 9, $C, D$ ).

\section{Non-neuronal tissues}

NGFRI staining in meninges started at E12, increased to very high levels between E14 to E18, and decreased gradually to a moderate level at PND10 (Table 5). The staining was on the cell surface and on some noncellular components. No such staining was seen with any of the negative control antibodies used.

The developing teeth became NGFRI positive at the tooth bud stage at E15. At the late cap stage of E20 embryos (Fig. $10 \mathrm{~A}$ ) and bell stage of later embryos, the inner enamel epithelium was very densely stained. Some cellular component in the dental sac of cap stage and in the primitive dental papilla of bell stage, which contain the neural crest-derived odontoblasts (Slavkin, 1979), were stained. The outer enamel epithelium was NGFRI negative. The mesenchyme tissues around the base of the dental structure were NGFRI positive. The staining of 192$\operatorname{lgG}$ in dental structures persisted to postnatal stages.

Muscle components were NGFRI positive at certain stages of development. NGFRI staining was seen in limb buds and somites as early as E11 (Fig. 2A). The staining on developing

\section{Table 4. NGFRI in other CNS structures ${ }^{a}$}

\begin{tabular}{|c|c|c|c|c|c|c|c|c|c|c|c|}
\hline Tissue & E11 & E12 & E13 & E14 & E15 & E16 & E18 & E20 & $\mathrm{PO}$ & P6 & P10 \\
\hline Subependymal cell & - & - & - & - & - & - & + & + & + & + & + \\
\hline Basal forebrain cholinergic cells & - & - & - & - & + & + & + & + & + & + & + \\
\hline Amygdala nucleus & - & - & - & - & - & - & - & \pm & \pm & \pm & - \\
\hline Cortex $^{b}$ & - & - & - & - & - & \pm & \pm & \pm & \pm & \pm & - \\
\hline \multicolumn{12}{|l|}{ Thalamus } \\
\hline I. VP & - & - & - & - & - & \pm & \pm & \pm & + & + & + \\
\hline II. LG & - & - & - & - & - & + & \pm & + & + & + & + \\
\hline Superior colliculus & nd & nd & nd & nd & nd & nd & - & \pm & \pm & \pm & \pm \\
\hline Medial terminal nucleus of acc. optic tract & nd & nd & nd & nd & nd & nd & - & - & + & + & ++ \\
\hline Superior olive & nd & nd & nd & nd & nd & + & + & + & + & \pm & - \\
\hline Lateral lemniscus and nucleus & nd & nd & nd & nd & nd & nd & \pm & \pm & \pm & \pm & - \\
\hline Reticular formation in brain stem & - & - & + & + & + & + & \pm & - & - & - & - \\
\hline Medial nucleus of inferior olive & nd & nd & nd & nd & - & + & + & + & + & + & - \\
\hline Cerebellum & nd & nd & nd & nd & \pm & + & + & + & + & ++ & +++ \\
\hline Deep cerebellar nucleus & nd & nd & nd & nd & nd & nd & nd & nd & + & ++ & + \\
\hline
\end{tabular}

a Relative NGFRI staining intensities are graded: $++t$, very strong; ++ , strong; + , moderate to weak; \pm , faint; - , absent; nd, not determined.

${ }^{b}$ At E16, the staining was seen in the hippocampal cortex; at E18-P6 the staining was seen in layers V and VI of the cerebral cortex. 


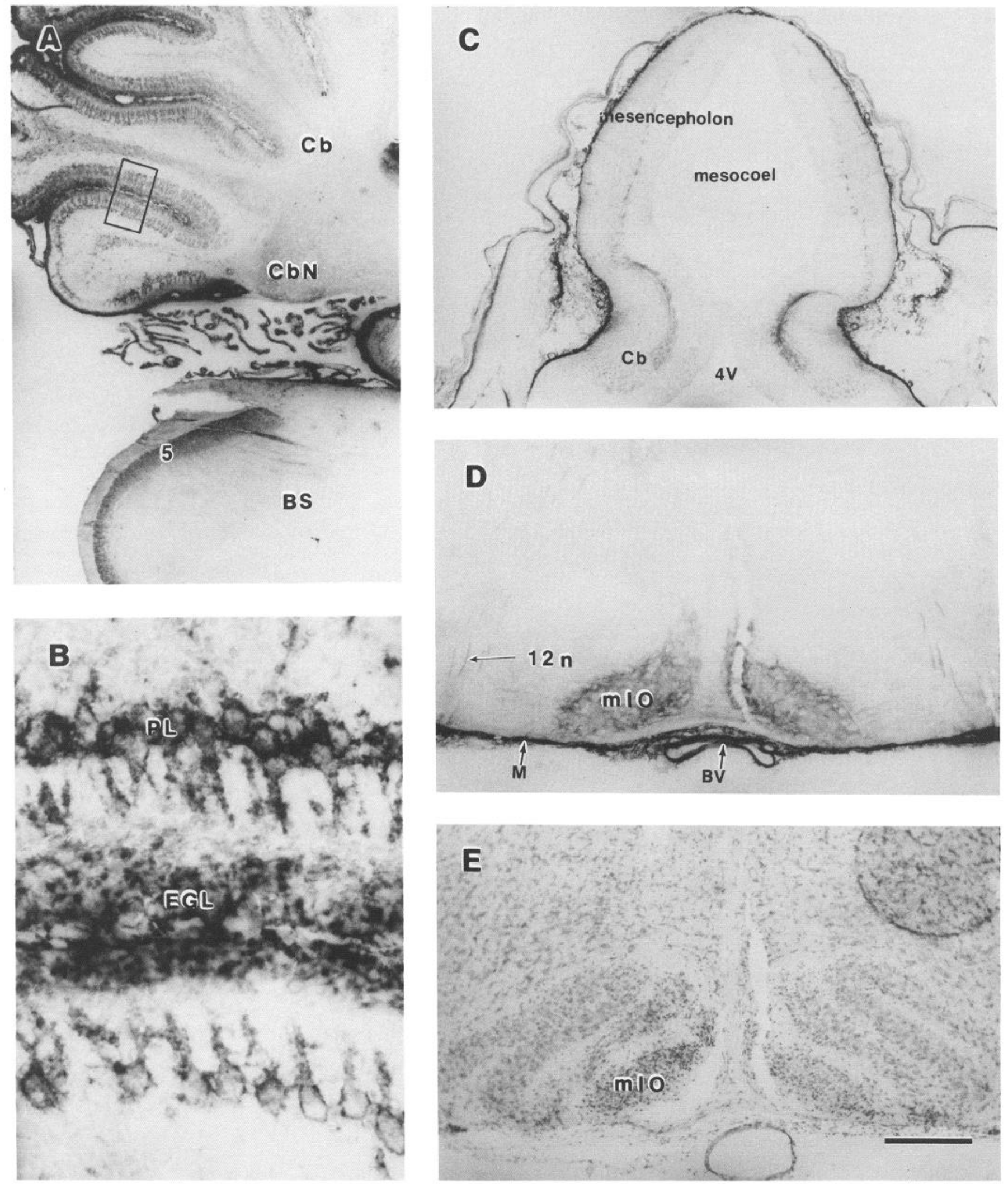

Figure 8. 192-IgG immunohistochemical staining of cerebellum and related structures. $A$, Cross section through cerebellum and brain stem at PND10. $B$, High-power view of the box in $A$. $C$, Frontal section of E16 head. D, Cross section through E20 brain stem. $E$, H\&E staining of the adjacent section of $D$. 5 , spinal tract of trigeminal nerve and its nucleus; $12 n$, hypoglossal nerve; $B S$, brain stem; $B V$, blood vessel; $C b$, cerebellum; $C b N$, deep cerebellar nuclei; $M$, meninges; $m I O$, medial nucleus of inferior olive. Scale bar (in $E$ ): $500 \mu \mathrm{m}, A$ and $C ; 200 \mu \mathrm{m}, D$ and $E$; and 50 $\mu \mathrm{m}, B$. 

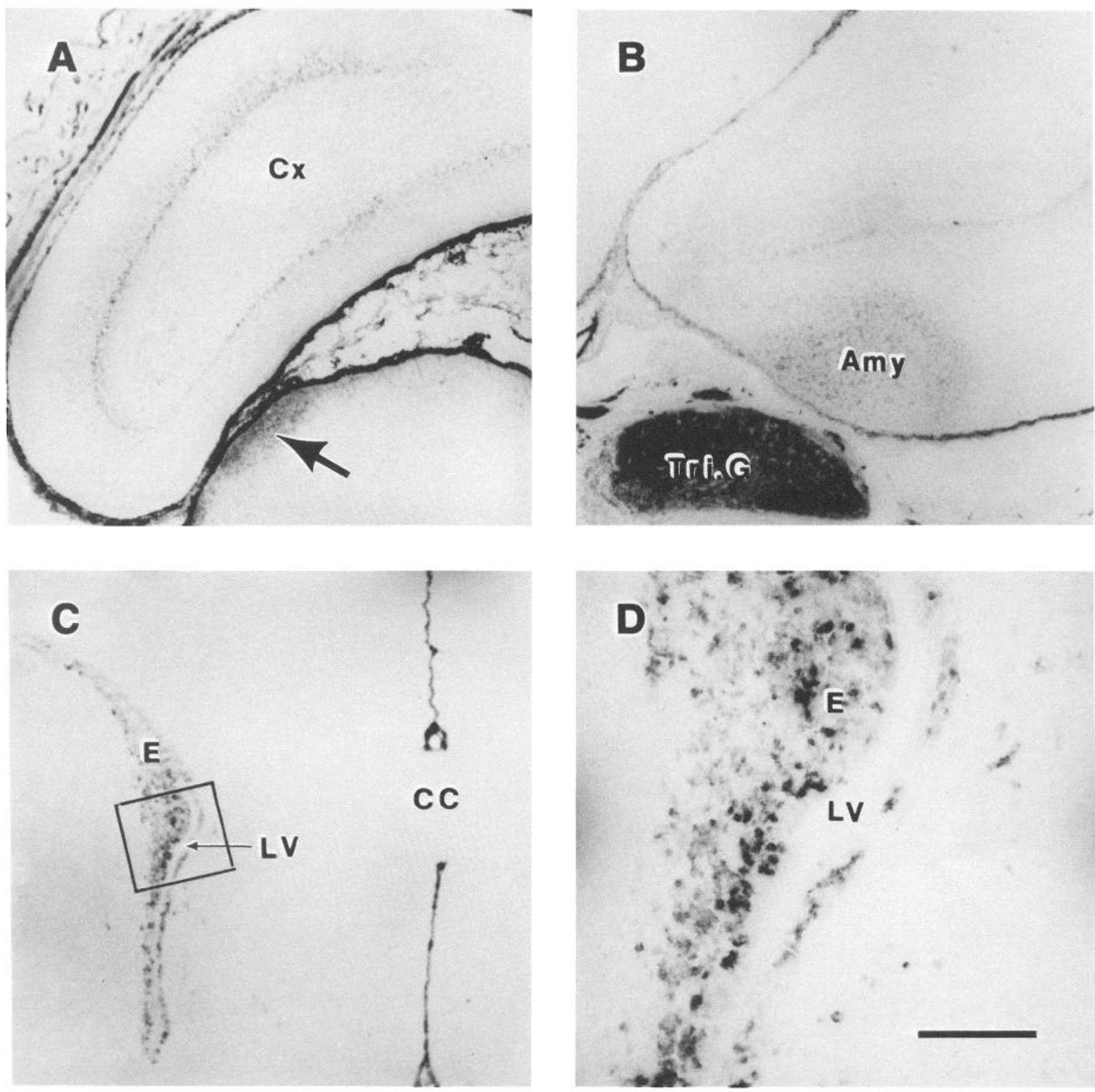

Figure 9. 192-IgG immunohistochemical staining of some CNS regions. $A$, Cross section of E20 cerebral cortex. $B$, Cross section of PND0 cerebral cortex. $C$, Cross section of PND10 brain. $D$, High-power view of the box in $C$. $A m y$, amygdaloid nuclei; $c c$, corpus callosum; $C x$, cerebral cortex; $E$, ependymal and subependymal layer; $L V$, lateral ventricle; Tri.G, trigeminal ganglion. Arrow in $A$ points to the superficial layer of superior colliculus. Scale bar (in $D$ ): $500 \mu \mathrm{m}, A-C ; 100 \mu \mathrm{m}, D$.

Table 5. NGFRI in non-neuronal tissues ${ }^{a}$

\begin{tabular}{|c|c|c|c|c|c|c|c|c|c|c|c|}
\hline Tissue & E11 & E12 & E13 & E14 & E15 & E16 & E18 & E20 & P0 & P6 & P10 \\
\hline Muscle components ${ }^{b}$ & +++ & nd & + & ++ & ++ & ++ & ++ & + & + & \pm & - \\
\hline Blood vessel & - & - & - & + & + & +++ & +++ & +++ & ++ & \pm & - \\
\hline Meninges & \pm & + & ++ & +++ & +++ & +++ & ++ & ++ & ++ & ++ & + \\
\hline Teeth $^{c}$ & nd & nd & nd & nd & + & ++ & ++ & ++ & ++ & ++ & nd \\
\hline Mesenchyme tissue around hair follicle & - & - & - & - & + & + & ++ & ++ & + & nd & nd \\
\hline Thymus & nd & nd & nd & nd & ++ & ++ & ++ & + & - & nd & nd \\
\hline
\end{tabular}

${ }^{a}$ Relative NGFRI staining intensities are graded: +++ , very strong; ++ , strong; + , moderate to weak; \pm , faint; - , absent; nd, not determined.

${ }^{b}$ At E11, the staining was in the limb buds and somites.

'At E15-E16, the staining was in the dental ridge, where the dental structures develop at a later stage. 

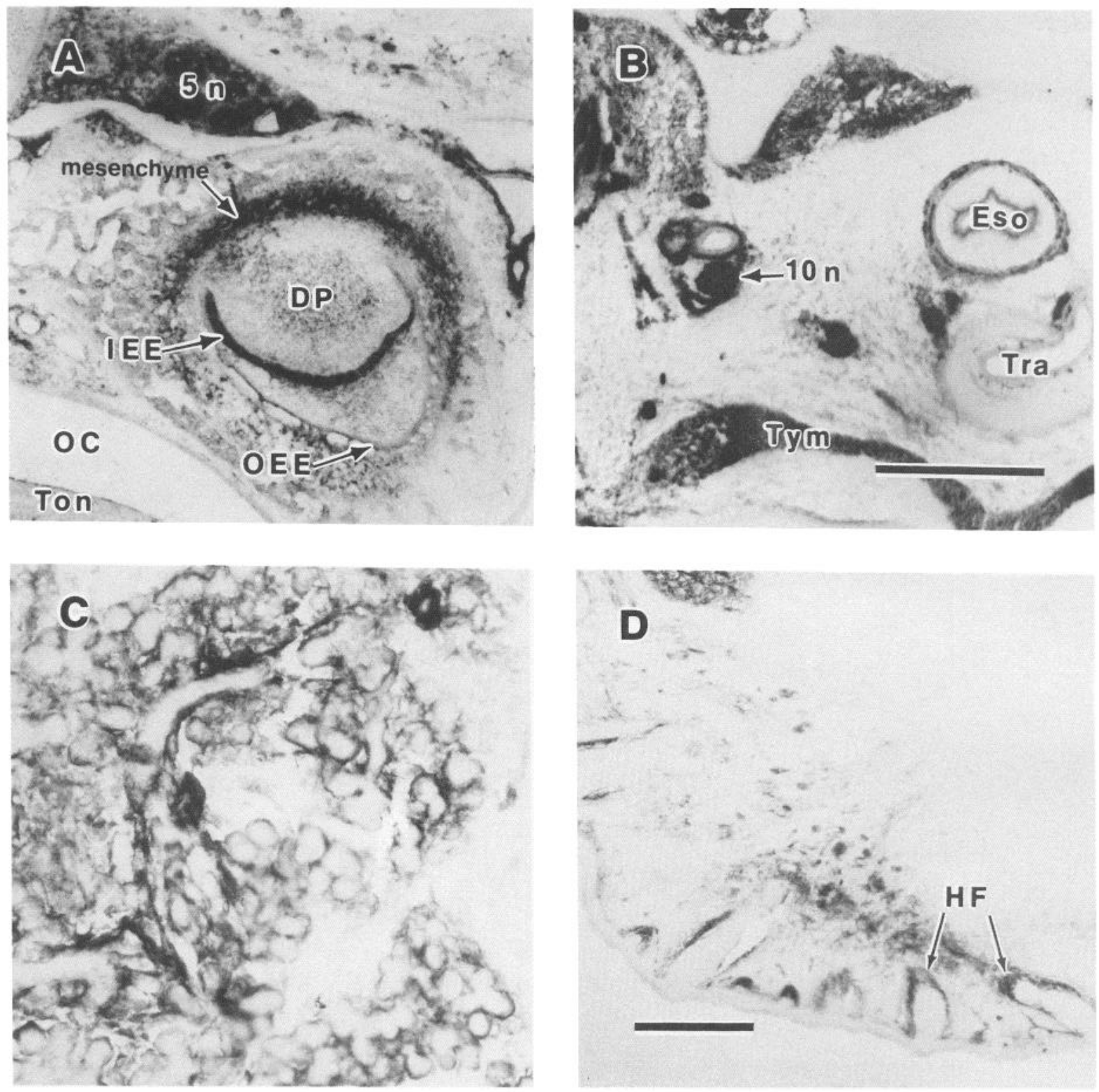

Figure 10. 192-IgG immunohistochemical staining of some non-neuronal tissues. $A$, Frontal section of E20 tooth. $B$, Cross section through E18 shoulder region. $C$, Frontal section through E20 salivary gland. $D$, Cross section of E18 head region. $5 n$, trigeminal nerve; $10 n$, vagus nerve; $D P$, dental papilla; $E s o$, esophagus; $H F$, hair follicle; $I E E$, inner enamel epithelium; $O C$, oral cavity; $O E E$, outer enamel epithelium; Ton, tongue; Tra, trachea; tym, thymus. Scale bar in $B: 500 \mu \mathrm{m}, A$ and $B$; scale bar in $D: 100 \mu \mathrm{m}, C ; 200 \mu \mathrm{m}, D$.

muscle became very dense at E15-E18 (Fig. 2, B, C). The density of staining in muscle declined after E20 to a very low level at PND6 and disappeared at PND10.

Thymus was NGFRI positive from E15 to E20, and the staining disappeared at PND0 (Fig. 10B). The mesenchyme tissues around the salivary glands (Fig. 10C), hair follicles (Fig. 10D), and other unidentified cranial structures were also positively stained by 192-IgG between E15 to PND0.

Blood vessels were positively stained by 192 -IgG starting at E14. The staining became very dense beteen E16-E20, declined afterwards, and disappeared by PND10. The staining was not seen on endothelium but was present on muscle wall and adventitia. Most blood vessels in the brain were not stained, but a few were occasionally positive.

\section{Discussion}

\section{Specificity of 192-IgG immunohistochemistry}

The present immunohistochemical study with 192-IgG showed NGFRI on the classical NGF targets and many other unexpected areas. The first issue to consider is the specificity of the staining observed with the monoclonal antibody against the rat NGF receptor. The $\mathrm{ABC}$ immunostaining method used was specific because 4 different control monoclonal IgGs used in the place of $192-\mathrm{IgG}$ as primary antibodies all gave negative results. The negative staining of E15 hamster with $192-\mathrm{IgG}$ indicated that the antigen recognized by $192-\mathrm{IgG}$ is species specific; this is consistent with the previous finding that $192-\mathrm{IgG}$ is an anti-rat NGF receptor antibody (Taniuchi and Johnson, 1985). The 
specificity of $192-\mathrm{IgG}$ as a probe for NGF receptor was originally established by (1) its ability to enhance NGF binding to the low-affinity receptor on $\mathrm{PC} 12$ cells; (2) binding to same number of binding sites on PC12 cells as does NGF (Chandler et al., 1984); (3) its retrograde transport from the rat anterior eye chamber to SCG in the same way as with NGF (Taniuchi and Johnson, 1985); (4) its ability to immunoprecipitate ${ }^{125}$ I-NGFlabeled membrane proteins from NGF-dependent tissues and PC12 cells (Taniuchi et al., 1986b). However, in addition to recognizing the NGF receptor, the antibody might conceivably bind to the same antigenic determinant on another molecule in NGFRI-positive sites shown in this study. Although this possibility cannot be absolutely ruled out, it appears that the unexpected positive sites shown here are true NGFRI. The reasons for that arc as follows: (1) When 192-IgG is used as an immunohistochemical probe for NGF receptor, the staining in NGF-dependent tissue such as SCG, DRG, and basal forebrain cholinergic neurons serves as a positive control for NGF receptor; (2) many NGFRI-positive sites seen in this study, including spinal motoneurons, embryonic muscle, and placode-derived sensory ganglia, are directly labeled by ${ }^{125}$ I-NGF with an autoradiographic method (Raivich et al., 1985, 1987; Richardson et al., 1986; Raivich and Kreutzberg, 1987); (3) in the crosslinkimmunoprecipitation assay, which requires NGF binding as well as 192-IgG binding, nodose ganglia express NGF receptor; (4) any other protein expressing a cross-reactive epitope must also be species specific; and (5) the specific retrograde transport of ${ }^{125}$ I-NGF in a receptor-mediated fashion from gastroenemius muscle to lumbar spinal motoneurons, as occurs in newborn rats, was inhibited by an excess of nonlabeled NGF (Yan et al., 1988).

Differential staining intensities (as shown in the tables) were relative and determined by microscopic examination of stained sections rather than from the photographs. The results reported here, as in all studies of this type, can vary slightly with different fixing and staining methods. This study, therefore, represents a semiquantitative description of the appearance of NGF receptor in developing rats. Because of the nature of the frozen-sectioning and immunohistochemical method used, only the large cellular components-such as basal forebrain cholinergic neurons, motoneurons in spinal cord and some brain-stem regions, Purkinje cells in the cerebellum, and sensory neurons in peripheral ganglia - can be discerned with the staining unequivocally on their cell surfaces. In situations where staining was identified by gross localization, such as sensory nuclei, some other CNS regions, and muscle mass, the specific immunopositive cells could not be determined.

\section{NGFRI in peripheral ganglia}

As shown in Figure $1 E$ and Table 1, 192-IgG stained SCG much less intensely than nodose ganglia. This result is surprising since rat SCG neurons respond to NGF as early as E15 (Lahtinen et al., 1986), required NGF for survival (Levi-Montalcini and Angcletti, 1968), and express high levels of NGF receptor pre- and postnatally (Yan and Johnson, 1987). In contrast, nodose ganglion neurons are placode-derived (Le Douarin, 1982) and do not require NGF for survival (Hedlund and Ebendal, 1980; Johnson et al., 1980; Pearson et al., 1983; Davies and Lindsay, 1985; Lindsay and Rohrer, 1985). To confirm that the NGFRI positivity was due to the bona fide NGF receptor, the 2-site immunoprecipitation assay was conducted as described in Materials and Methods. Because this assay requires both NGF and
192-IgG to bind specifically to the receptor protein, it is, in principle, more specific for the measurement of NGF receptor than 192-IgG immunohistochemistry. The latter is a 1-site immunoassay and might therefore produce false-positive results. The 2-site immunoprecipitation data showed that the NGF receptor content in nodose ganglion was about 50\% more than in SCG on a per milligram protein basis. Although the immunohistochemical method is not as quantitative as the immunoprecipitation assay, the difference in the density of NGFRI staining between nodose ganglia and SCG seems much more than 50\% (see Fig. $1 E$ ). This apparent discrepancy can probably be explained with the assumption that when used immunohistochemically, 192-IgG recognizes only the low-affinity form of the NGF receptor and not the intact high-affinity receptor (Chandler et al., 1984; but see Green and Greene, 1986). Results from our laboratory also suggest that 192 -IgG, when used as an immunohistochemical tool, binds only to low-affinity receptors on cells (unpublished results). The present immunohistochemical study suggests that in early development nodose neurons express low-affinity NGF receptors and do so in greater abundance than does the SCG. Since neurotrophic effects of NGF are associated with high-affinity receptors (Tischler and Greene, 1975; Zimmerman et al., 1978; Sutter et al., 1979), low-affinity receptors on nodose neurons would not be expected to mediate neurotrophic effects. SCG expresses both high- and low-affinity NGF receptors, and the former mediates the biological effects of NGF but cannot be recognized immunohistochemically by 192 -IgG. Therefore, the density of staining for NGF receptor in SCG was much less than that in nodose ganglia. In the immunoprecipitation assay, we believe that the NGF-binding protein of the high-affinity receptor is dissociated from other component(s) by solubilization, thereby generating in solution the low-affinity, 192-IgG-recognizable form. Therefore, the crosslink-immunoprecipitation assay of detergent-solubilized receptor actually measures more closely the total amount of (high- and low-affinity) NGF binding sites. Because SCG expresses the highaffinity receptor but nodose ganglia may not (but see Richardson et al., 1986), the difference of total amount NGF receptor as determined by the quantitative assay between these 2 tissues is not as great as would be observed by immunohistochemistry with 192-IgG. A final resolution of this issue will have to await the availability of antibodies that clearly recognize both forms of the NGF receptor.

Similarly, neural crest-derived sensory ganglia, which are NGFdependent tissues (Levi-Montalcini and Angeletti, 1968; Johnson et al., 1980), showed less NGFRI staining than placodederived sensory ganglia, which arc not NGF dependent (Johnson et al., 1980; Pearson et al., 1983). Here again, we suggest that the reason is that placode-derived sensory ganglia express only the low-affinity NGF receptor recognized by 192-IgG immunohistochemistry. The neural crest-derived sensory ganglia express less low-affinity receptor but, in addition, express 192IgG-unrecognizable high-affinity NGF receptor, which mediates neurotrophic effects of NGF.

The staining was relatively evenly distributed in ganglia, indicating that all the neurons were positive for NGFRI. It is known that non-neuronal cells in developing ganglia (Sutter et al., 1979; Carbonetto and Stach, 1982; Zimmerman and Sutter, 1983; Rohrer, 1985) and in developing (DiStefano and Johnson, 1988a) and injured (Taniuchi et al., 1986a) sciatic nerve express the low-affinity NGF receptor. Non-neuronal satellite cells in ganglia likely contribute to the staining. 
It is interesting to note that with the autoradiographic method, NGF binding sites are also found in placode-derived sensory ganglia and vestibulocochlear ganglia at low levels in chicken embryos (Raivich et al., 1987) and in nodose ganglia of adult rats (Richardson et al., 1986). The biological significance of the NGF receptor in the placode-derived sensory ganglia and neural crest-derived parasympathetic ganglia requires further investigation.

\section{NGFRI in motoneurons}

It is generally accepted that NGF has no effect on motoneurons in the ventral spinal cord since the application of NGF during the time of naturally occurring motoneuron cell death does not increase motoneuron survival (Oppenheim et al., 1982) and ${ }^{125} \mathrm{I}$ NGF is not retrogradely transported from nerve terminals to motoneurons in the spinal cord of E10 chicken embryos (Brunso-Bcchtold and Hamburger, 1979) and in adult rat (Stockel et al., 1975). However, with autoradiography, Raivich et al. (1985) found specific NGF binding sites expressed in the lateral motor column of chicken embryos between E4 to E12. In this study, we confirmed their observation in rats and found that NGFRI was expressed in ventral spinal cord at E11 and reached a peak at E13. After E15 the staining was restricted to the lateral motor column. The density of staining in the motoneurons increased to another peak at PND0 and disappeared at PND10. The motor nuclei of trigeminal, abducens, facial, ambiguus, and hypoglossal in brain stem also expressed NGFRI, and the change of the staining density followed essentially the same temporal pattern as seen in spinal cord during the period of E15-PND10. The capability of the lumbar ventral spinal motoneurons of PND0 rats to specifically transport ${ }^{125} \mathrm{I}-\mathrm{NGF}$ and ${ }^{125} \mathrm{I}-192-\mathrm{IgG}$ retrogradely from their terminal fields to their cell bodies (Yan et al., 1988) confirms that these motoneurons do express true NGF receptors at certain stages of development. Because NGFRI completely disappeared from brain stem and spinal motoneurons at PND10, it is consistent with the literature that no ${ }^{125} \mathrm{I}-$ NGF binding is seen in brain-stem motor nuclei of adult rats (Richardson et al., 1986; Raivich and Kreutzberg, 1987), and no retrograde transport of ${ }^{125} \mathrm{I}-\mathrm{NGF}$ to spinal motoneurons is observed in adult rats (Stockel et al., 1975).

It is interesting that the expression of NGFRI in ventral spinal cord shows 2 phases. The first phase is very early (E11-E 14) in development, and the onset of NGFRI expression follows a rostral to caudal gradient pattern. During this period, the major cellular components in the ventral spinal cord are postmitotic motoneurons undergoing differentiation, i.e., neurite outgrowth, synapse formation, and cell death. The second phase of NGF receptor staining was between E15 to PND6. The density of staining increased from E15 to peak at about PND0. The staining was confined to the lateral motoneuron column, and individual neurons could be recognized with surface staining. At the same time, the change of the density of NGFRI staining in DRG, dorsal horn, and muscle mass followed a similar time course as that seen in lateral motoneuron column. Because these 3 components interconnect to form a functional chain, it is possible that NGF receptor might play some role in the establishment of the connection of the motoneuron-muscle effectorsensory neuron-motoneuron loop in development or the expression of NGF receptor in this system may be regulated by a common factor.

\section{NGFRI in other CNS structures}

NGF has recently been shown to have neuronotrophic effects on cholinergic neurons in the basal forebrain (Gnahn et al., 1983) and striatum (Mobley et al., 1985; see review by Johnson and Taniuchi, 1987). Several studies in the literature have demonstrated the colocalization of NGF receptor, or binding sites, and choline acetyltransferase or acetylcholinesterase activity in these neurons (Hefti et al., 1986; Richardson et al., 1986; Raivich and Kreutzberg, 1987; Springer et al., 1987). In this study, NGFRI staining was seen in basal forebrain nucleus basalis complex starting at E15. At about this stage of the development, this nucleus complex is formed in rat (Bayer, 1979) and expresses the cholinergic phenotype in human (Kostovic, 1986). With the differentiation of this complex, staining was seen in the nucleus of the diagonal band of Broca, the nucleus of the medial septum, and the nucleus basalis throughout the rest of the time examined. Our findings suggest that NGF may produce a trophic, or some other, effect for these basal forebrain cholinergic neurons at a very early stage. With 192-IgG, we did not see any staining in striatum, which is known to have NGFresponsive cholinergic neurons (Mobley et al., 1985). Autoradiographic studies show high-affinity binding sites in this structure in adult rats (Richardson et al., 1986; Raivich and Kreutzberg, 1987). The inability to demonstrate NGFRI staining in this structure may be because (1) the striatal cholinergic neurons express very little NGF receptor before PND10 (the autoradiographic studies are done with adult rats); (2) the striatal cholinergic neurons express primarily the high-affinity NGF receptor, which may not be recognized by $192-\mathrm{IgG}$ (see discussion above), although they can be detected by NGF autoradiography.

It is interesting that cells in the subventricular/subependymal layer express NGF receptor. The staining occurred only in a very small area in the medial part of the lateral ventricle prenatally and spread rostrally to the olfactory bulb and to the lateral wall of the lateral ventricle postnatally. This cell layer is known to be mitotically active pre- and postnatally and is considered to give rise to nerve cells (Altman, 1969; Bayer, 1983; Kaplan et al., 1985) and glial cells (Paterson et al., 1973; Imamoto et al., 1978; Korr, 1980). There is a rostral migratory stream of subependymal cells from the level of the anterior lateral ventricle to the olfactory bulb postnatally, and these cells eventually differentiate into granule cells (Altman, 1969; Kishi, 1987). The pattern of the staining seen in this study suggests that the premigrating granule cells might express NGF receptor.

The staining in cerebellum is striking. Metencephalon or cerebellar anlage showed antibody staining at a very early stage. With differentiation of the cerebellum postnatally, the staining became more distinct. The staining was clearly seen on the surface of Purkinje cell bodies and dendrites. Double labeling with anti-GFAP antibodies showed that the Bergman radial glial cells were NGFRI negative (data not shown). Staining was also seen on the external granule cells, but not on the internal granule cells, suggesting that only the premigratory granule cells express NGF receptor. The NGFRI staining disappeared at PND15, when cerebellar differentiation was largely completed. Whether NGF has any trophic effects on these NGFRI-positive cerebellar neurons and what is the biological significance of the NGF receptor expression during cerebellum development are unknown, but the issue deserves further study. 


\section{NGFRI in non-neuronal tissues}

Many non-neuronal tissues showed NGFRI staining in this study. Some of them, such as pia mater, teeth, and cranial muscle, contain cellular components derived from neural crest which may retain the ability to produce NGF receptor even after differentiating into non-neuronal tissues. In addition to those neural crest-derived non-neuronal cells, staining was seen on mesodermally derived structures. Most striking was the staining on limb buds, somites, and muscle mass. Again, this staining pattern was very similar to that reported by Raivich et al. (1985, 1987) with ${ }^{125}$ I-NGF autoradiography in chicken embryos. This concordance of results from different methods argues strongly for the presence of NGF receptor sites in these unexpected locations. We also observed 192-IgG staining in other mesodermal structures, including tissue around hair follicles and salivary glands, and adventitia of blood vessels. Although the most straightforward interpretation of our results and those of Raivich et al. $(1985,1987)$ is that cells in these structures make and present NGF receptors on the cell surface, other possibilities exist. For example, studies in our laboratory (DiStefano and Johnson, 1988b) have shown that a truncated form of the NGF receptor circulates in the developing animal, decreasing markedly from E19 (earliest studied) through adulthood. It remains possible that some of the positive staining and binding observed occurs because this truncated receptor is sequestered or bound to tissues such as blood vessel walls. Developmental studies with in situ hybridization by using cDNA probes against NGF receptor should resolve any remaining issues of the site of synthesis observed with immunohistochemical or binding methods.

In summary, NGF receptor expression was assessed by a monoclonal antibody against the rat receptor. NGF receptor was localized to many unexpected locations, both neuronal and non-neuronal. This confirmed many similar observations made by Raivich and colleagues. We suggest that many of these structures bear only low-affinity receptors. These results suggest either that NGF receptor is expressed in places where it has no developmental function or that NGF exerts effects, both in the $\mathrm{CNS}$ and in the periphery, other than those traditionally ascribed to the molecule.

\section{References}

Altman, J. (1969) Autoradiographic and histological studies of postnatal neurogenesis. IV. Cell proliferation and migration in the anterior forebrain, with special reference to persisting neurogenesis in the olfactory bulb. J. Comp. Neurol. 137: 433-458.

Barde, Y-A., D. Edgar, and H. Thoenen (1980) Sensory neurons in culture: Changing requirements for survival factors during embryonic development. Proc. Natl. Acad. Sci. USA 77: 1199-1203.

Bayer, S. A. (1979) The development of the septal region in the rat. J. Comp. Neurol. 183: 89-106.

Bayer, S. A. (1983) ${ }^{3} \mathrm{H}$-thymidine-radiographic studies of neurogenesis in the rat olfactory bulb. Exp. Brain Res. 50: 329-340.

Bocchini, V., and P. U. Angeletti (1969) The nerve growth factor: Purification as a 30,000 molecular weight protein. Proc. Natl. Acad. Sci. USA 64: 787-794.

Brunso-Bechtold, J. K., and V. Hamburger (1979) Retrograde transport of nerve growth factor in chicken embryo. Proc. Natl. Acad. Sci. USA 76: 1494-1496.

Carbonetto, S., and R. Stach (1982) Localization of nerve growth factor bound to neurons growing nerve fibers in culture. Dev. Brain Res. 3 . 463-473.

Chandler, C. E., L. M. Parsons, M. Hosang, and E. M. Shooter (1984)
A monoclonal antibody modulates the interaction of nerve growth factor with PC12 cells. J. Biol. Chem. 259: 6882-6889.

Cochard, P., M. Goldstein, and I. B. Black (1978) Ontogenetic appearance and disappearance of tyrosine hydroxylase and catecholamines in the rat embryo. Proc. Natl. Acad. Sci. USA 75: 2986-2990.

Davies, A. M., and R. M. Lindsay (1985) The cranial sensory ganglia in culture: Differences in the response of placode-derived and neural crest-derived neurons to nerve growth factor. Dev. Biol. 111: 62-72.

Dimberg, Y., and T. Ebendal (1987) Effects of nerve growth factor on autonomic neurons in the chick embryo: A stereological study. Int. J. Dev. Neurosci. 5: 195-205.

DiStefano, P. S., and E. M. Johnson, Jr. (1988a) Nerve growth factor receptors on cultured rat Schwann cells. J. Neurosci. 8: 231-241.

DiStefano, P. S., and E. M. Johnson, Jr. (1988b) Identification of a truncated form of the nerve growth factor receptor. Proc. Natl. Acad. Sci. USA 85: 270-274.

Gnahn, H., F. Hefti, R. Heumann, M. E. Schwab, and H. Theonen (1983) NGF-mediated increase of choline acetyltransferase (ChAT) in the neonatal rat forebrain: Evidence for a physiological role of NGF in the brain? Dev. Brain Res. 9: 45-52.

Green, S. H., and L. A. Greene (1986) A single $\mathrm{Mr}=103,000{ }^{125} \mathrm{I}-\beta$ nerve growth factor-affinity-labeled species represents both the low and high affinity forms of the nerve growth factor receptor. J. Biol. Chem. 261: 15316-15326.

Hedlund, K. O., and T. Ebendal (1980) The chick embryo nodose ganglion: Effects of nerve growth factor in culture. J. Neurocytol. 9: 665-682.

Hefti, F., J. Hartikka, A. Salvatierra, W. J. Weiner, and D. C. Mash (1986) Localization of nerve growth factor receptors in cholinergic neurons of the human basal forebrain. Neurosci. Lett. 69: 37-41.

Herrup, K., and E. M. Shooter (1975) Properties of the $\beta$-nerve growth factor receptor in development. J. Cell Biol. 67: 118-125.

Imamoto, K., J. A. Paterson, and C. P. Leblond (1978) Radioautographic investigation of gliogenesis in the corpus callosum of young rats. J. Comp. Neurol. 180: 115-138.

Johnson, E. M., Jr., and M. Taniuchi (1987) Nerve growth factor (NGF) receptors in the central nervous system. Biochem. Pharmacol. 36: 4189-4195.

Johnson, E. M., Jr., P. D. Gorin, L. D. Brandeis, and J. Pearson (1980) Dorsal root ganglion neurons are destroyed by exposure in utero to maternal antibody to nerve growth factor. Science 210: 916-918.

Jonakait, G. M., J. Wolf, P. Cochard, M. Goldstein, and I. B. Black (1979) Selective loss of noradrenergic phenotypic characters in neuroblasts of the rat embryo. Proc. Natl. Acad. Sci. USA 76: 46834686.

Kaplan, M. S., N. A. McNelly, and J. W. Hinds (1985) Population dynamics of adult-formed granule neurons of the rat olfactory bulb. J. Comp. Neurol. 239: 117-125.

Kishi, K. (1987) Golgi studies of the development of granule cells of the rat olfactory bulb with reference to migration in the subependymal layer. J. Comp. Neurol. 258: 112-124.

Korr, H. (1980) Proliferation of different cell types in the brain. Adv. Anat. Embryo. Cell Biol. 60: 1-72.

Kostovic, I. (1986) Prenatal development of nucleus basalis complex and related fiber systems in man: A histochemical study. Neuroscience 17: 1047-1077.

Lahtinen, T., S. Soinila, and O. Eranko (1986) Age-dependent stimulation by atrium explants or nerve growth factor of nerve fibre outgrowth from cocultured embryonic rat sympathetic ganglia. Dev. Brain Res. 27: 51-57.

Le Douarin, N. M. (1982) The Neural Crest, Cambridge U. P., New York.

Levi-Montalcini, R., and P. U. Angeletti (1968) The nerve growth factor. Physiol. Rev. 48: 534-569.

Lindsay, R. M., and H. Rohrer (1985) Placodal sensory neurons in culture: Nodose ganglion neurons are unresponsive to NGF, lack NGF receptors but are supported by a liver-derived neurotrophic factor. Dev. Biol. 112: 30-48.

Marchalonis, J. J. (1969) An enzyme method for the trace iodination of immunoglobulins and other proteins. Biochem. J. 113: 229-305.

Mobley, W. C., J. L. Rutkowski, G. I. Tennekoon, K. Buchanan, and M. V. Johnston (1985) Choline acetyltransferase activity in striatum 
of neonatal rats increased by nerve growth factor. Science $229: 284$ 287.

Oppenheim, R. W., J. L. Maderdrut, and D. J. Wells (1982) Cell death of motoncurons in the chick embryo spinal cord. VI. Reduction of naturally occurring cell death in the thoracolumbar column of Terni by nerve growth factor. J. Comp. Neurol. 210: 174-189.

Paterson, J. A., A. Privat, E. A. Ling, and C. P. Leblond (1973) Investigation of glial cells in semithin sections. III. Transformation of subependymal cells into glial cells, as shown by radioautography after ${ }^{3} \mathrm{H}$-thymidine injection into the lateral ventricle of the brain of young rats. J. Comp. Neurol. 149: 83-102.

Pearson, J., E. M. Johnson, and L. Brandeis (1983) Effects of antibodies to nerve growth factor on intrauterine development of derivatives of cranial neural crest and placode in the guinea pig. Dev. Biol. 96: 3236.

Raivich, G., and G. W. Kreutzberg (1987) The localization and distribution of high affinity $\beta$-nerve growth factor binding sites in the central nervous system of the adult rat. A light microscopic autoradiographic study using [ $\left.{ }^{125} \mathrm{I}\right] \beta$-nerve growth factor. Neuroscience 20 : 23-36.

Raivich, G., A. Zimmermann, and A. Sutter (1985) The spatial and temporal pattern of $\beta$ NGF receptor expression in the developing chick embryo. EMBO J. 4: 637-644.

Raivich, G., A. Zimmermann, and A. Sutter (1987) Nerve growth factor (NGF) receptor expression in chicken cranial development. J. Comp. Neurol. 256: 229-245.

Richardson, P. M., V. M. K. Verge Issa, and R. J. Riopelle (1986) Distribution of neuronal receptors for nerve growth factor in the rat. J. Neurosci. 6: 2312-2321.

Rohrer, H. (1985) Nonneuronal cells from chick sympathetic and dorsal root sensory ganglia express catecholamine uptake and receptors for nerve growth factor during development. Dev. Biol. 111: 95107.

Slavkin, H. C. (1979) Developmental Craniofacial Biology, Lea \& Febiger, Philadelphia.

Springer, J. E., S. Koh, M. W. Tayrien, and R. Loy (1987) Basal forebrain magnocellular neurons stain for nerve growth factor receptor: Correlation with cholinergic cell bodies and effects of axotomy. J. Neurosci. Res. 17: 111-118.
Stackel, K., M. Schwab, and H. Thoenen (1975) Comparison between the retrograde axonal transport of nerve growth factor and tetanus toxin in motor, sensory and adrenergic neurons. Brain Res. 99: 1-16.

Sutter, A., R. J. Riopclle, R. M. Harris-Warrick, and E. M. Shooter (1979) The heterogeneity of nerve growth factor receptors. In Transmembrane Signaling (Prog. Clin. Biol. Res.), M. Bilensky, R. J. Collier, D. F. Steiner, and C. F. Fox, eds., pp. 659-667, Liss, New York.

Taniuchi, M., and E. M. Johnson, Jr. (1985) Characterization of the binding properties and retrograde axonal transport of a monoclonal antibody directed against the rat nerve growth factor receptor. J. Cell Biol. 101: 1100-1106.

Taniuchi, M., H. B. Clark, and E. M. Johnson, Jr. (1986a) Induction of nerve growth factor receptor in Schwann cells after axotomy. Proc. Natl. Acad. Sci. USA 83: 4094-4098.

Taniuchi, M., J. B. Schweitzer, and E. M. Johnson, Jr. (1986b) Nerve growth factor receptor molecules in rat brain. Proc. Natl. Acad. Sci. USA 83: 1950-1954.

Tischler, A. S., and L. A. Greene (1975) Nerve growth factor-induced process formation of cultured rat pheochromocytoma cells. Nature 258: $341-342$.

Yan, Q., and E. M. Johnson, Jr. (1987) A quantitative study of the developmental expression of nerve growth factor (NGF) receptor in rats. Dev. Biol. 121: 139-148.

Yan, Q., W. D. Snider, J. J. Pinzone, and E. M. Johnson, Jr. (1988) Retrograde transport of nerve growth factor (NGF) in motoneurons of developing rats: Assessment of potential neurotrophic effects. Neuron $1: 335-343$.

Yip, H. K., and E. M. Johnson, Jr. (1987) Nerve growth factor receptors in rat spinal cord: An autoradiographic and immunohistochemical study. Neuroscience 22: 267-279.

Zimmerman, A., and A. Sutter (1983) $\beta$-Nerve growth factor ( $\beta N G F$ ) receptors on glial cells. Cell-cell interaction between neurons and Schwann cells in cultures of chick sensory ganglia. EMBO J. 2: 879885 .

Zimmerman, A., A. Sutter, J. Samuelson, and E. M. Shooter (1978) A serological assay for the detection of cell surface receptors of nerve growth factor. J. Supramol. Struct. 9: 351-361. 